\title{
تقيم الكفاءة التعليمية لمعلمي الطلبة ذوي الإعاقة العقلية
}

\author{
اعداد \\ د. ضرار محمد القضاة \\ قسم التربية الخاصدة \\ كلية التربية - جامعة أم القرى الهربه \\ مكة المكرمة - المملكة العربية السعودية
}

مجلة بحوث التربية النوعية ـ جامعة المنصورة

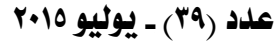


تقيه الكناءة التهليمية المهلمي الطلبة ذوي الإعاقة العقلية

إعداد

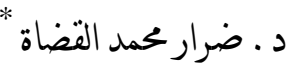

\section{هلفص البحث:}

هـدفت الدراسـة الحاليسة إلى تقيـيم مستوى الكفـاءة التعليميسة لمعلمسي الطلاب ذوي الإعاقـة

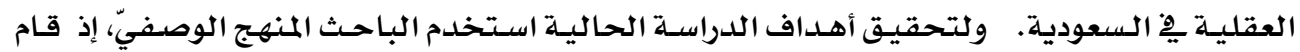

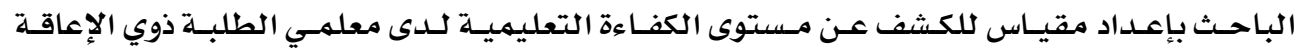

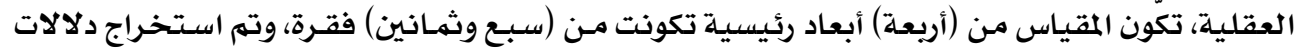
الصدق والثبات اللازمة للمقياس.

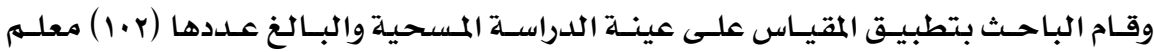

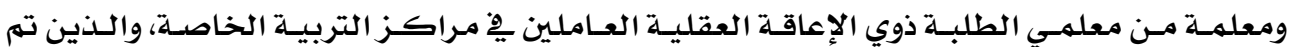
اختيارهم بطريقة عشوائية من مككة المكرمـة وجلدة.

ولإججابة عن سؤال الدراسـة المتعلق بمستوى الكفـاءة التعليميـة لمعلمي الطلبـة ذوي الإعاقـة

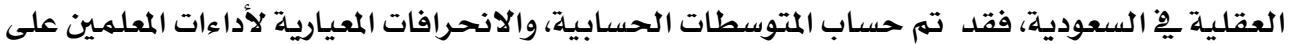

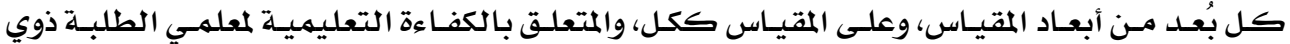

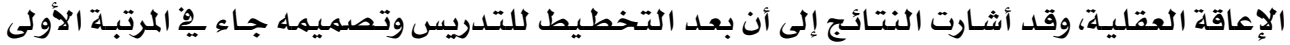

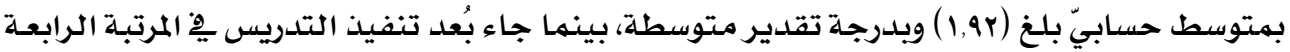

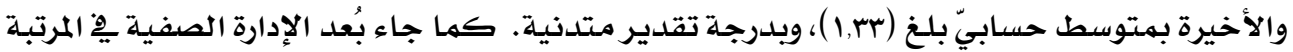

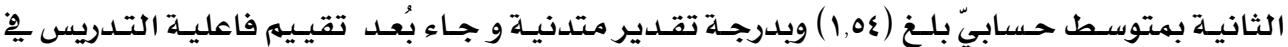

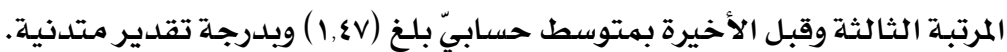

الاقدهمة:

يعدّ التقويم خطوة هامـة ومحطة مـن المحطـات التي لا بـد مـن الوقوف عندها لمعرفـة صـحة

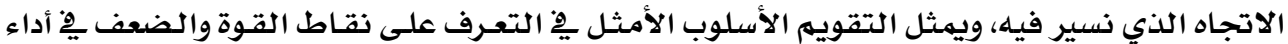

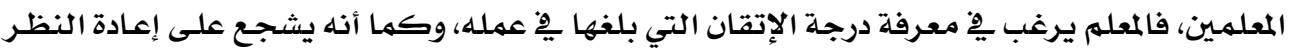

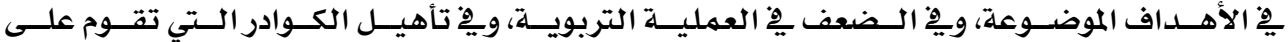

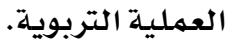

* قسم التربية الخاصة كلية التربية - جامعة أم القرى - مكة المكرمة - المملكة العربية السعودية 


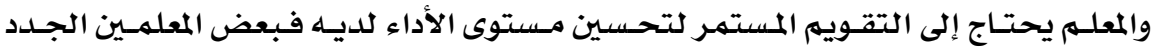

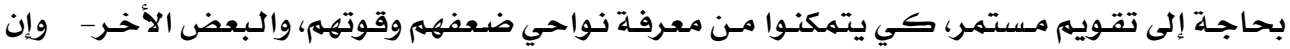

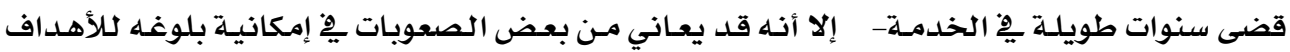

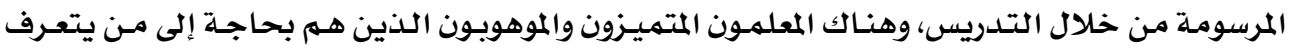

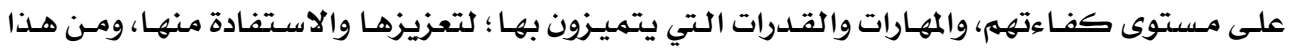

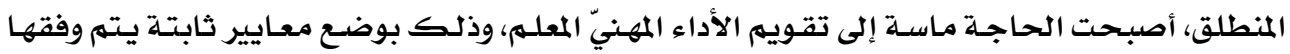
ذلك التقويم.

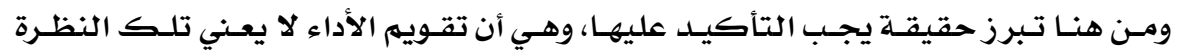

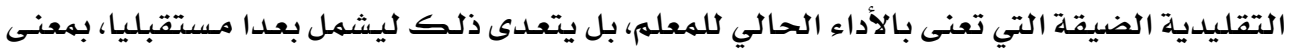

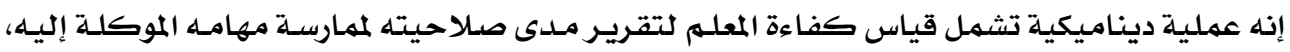

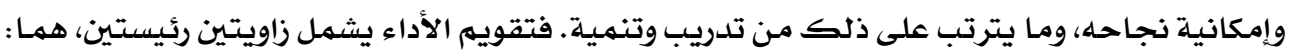

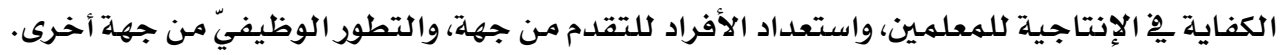

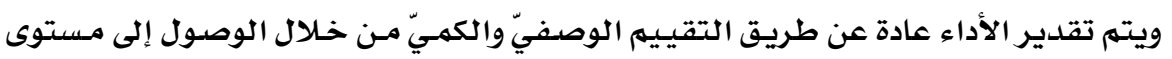

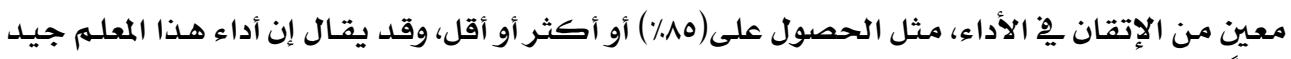

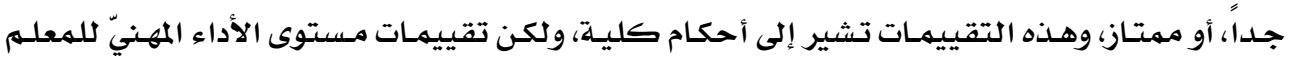

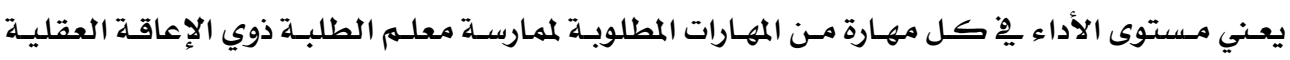

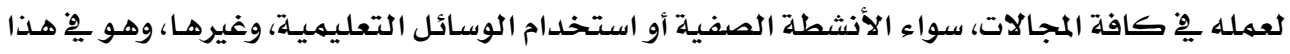

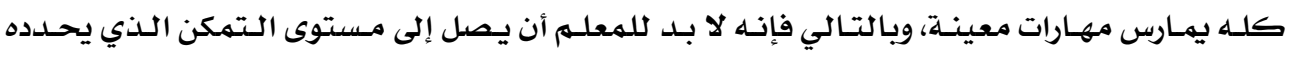

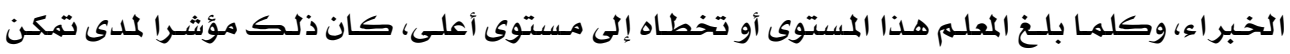

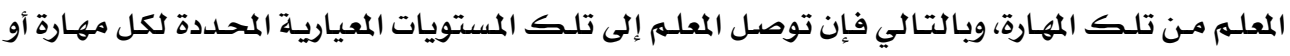

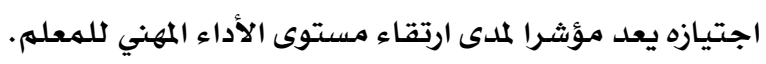

\section{همشكلة الدراسة}

إن المتمعن يِّواقع تربية وتعليم الطلبة من ذوي الإعاقة العقليـة يف السعودية يمكنه القول:

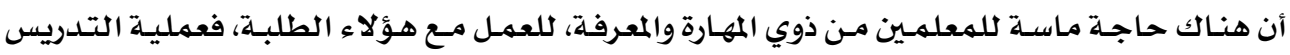

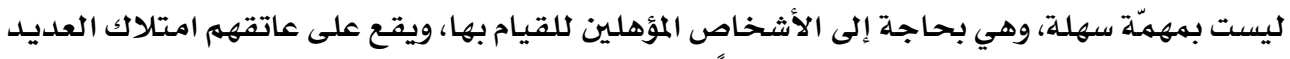

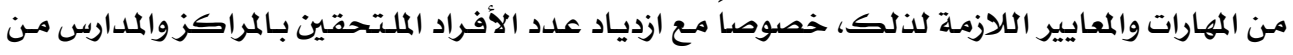

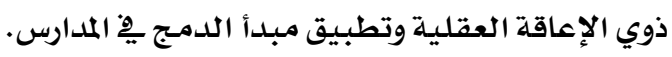

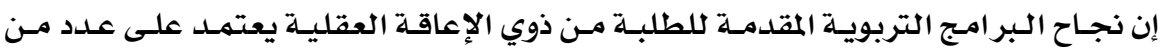

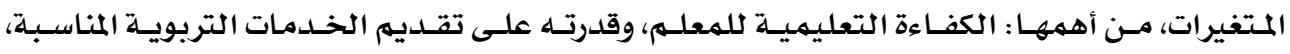

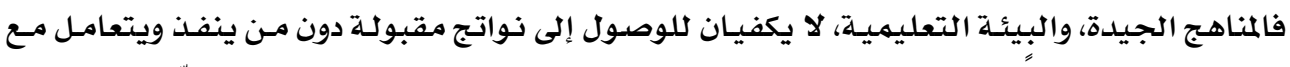

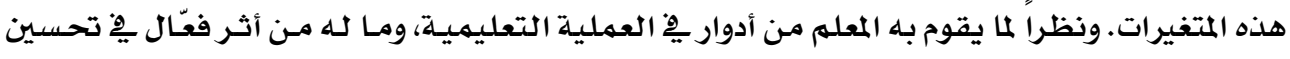

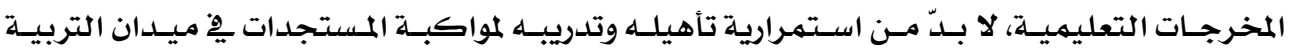




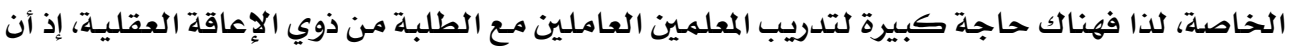

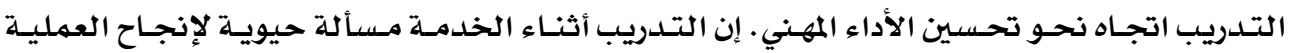

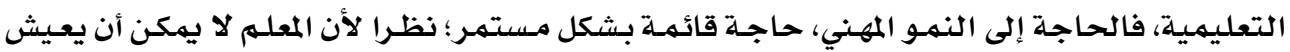

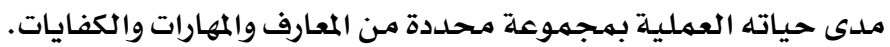

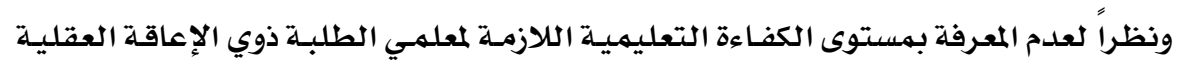

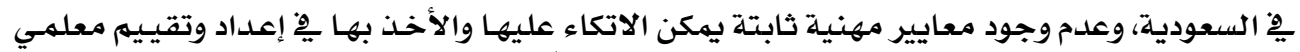

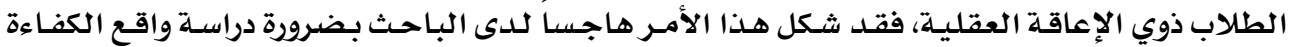
التعليمية التي يمتلكها معلمو الطلاب ذوي الإعاقة العقلية دراسة علمية موضوعية. ومن هذا المنطلق فإن مشكلة الدراسـة تتمثل بالإجابة على السؤال التالي:

ما مستوى الكفاءة التعليمية لمعلمي الطلاب ذوي الإعاقة العقلية فِ السعودية؛ أهداف الدراسة : تهدف هذه الدراسـة إلى تقييم مستوى الكفاءة التعليمية لمعلمي الطلبة ذوي الإعاقة العقلية مِ في السعودية. أهمئة الثدراسة: من المتوقع أن يوفر هذا البحث معلومات مهمة عن الكفاءة التعليمية، والممارسات التدريسية

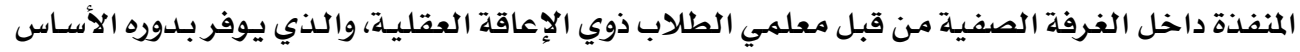

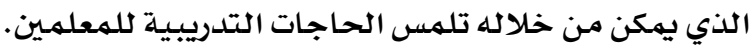

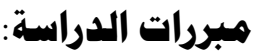

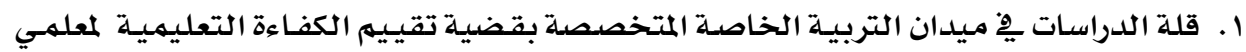

$$
\text { الطلاب ذوي الإعاقة العقلية. }
$$

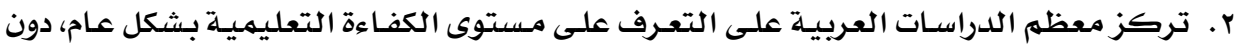

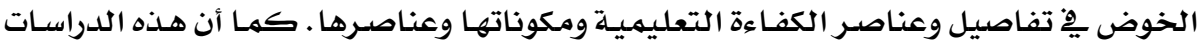

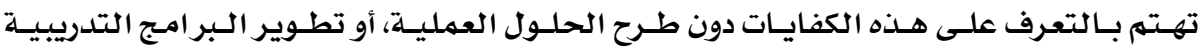
للنهوض بالمعلمـين.

\section{الدراسات السابقة}

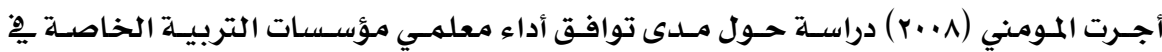

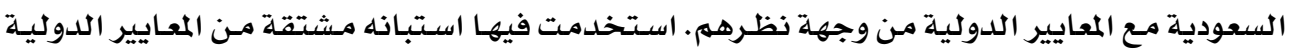

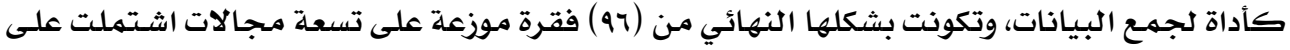

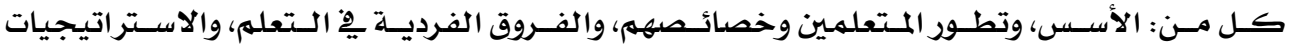

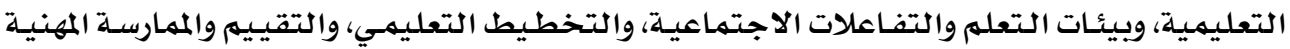




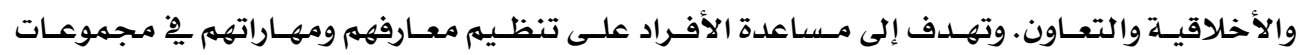

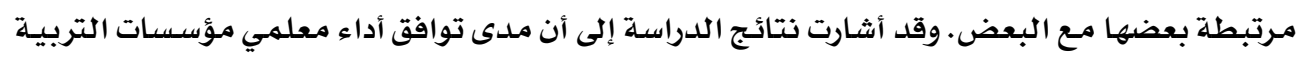

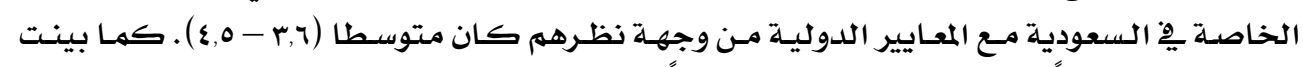

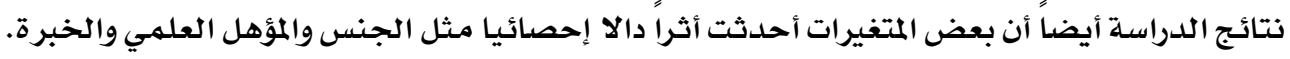

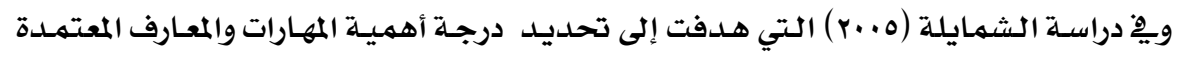

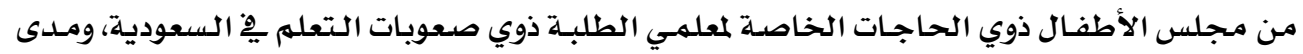

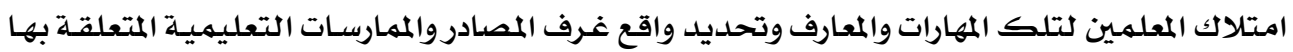

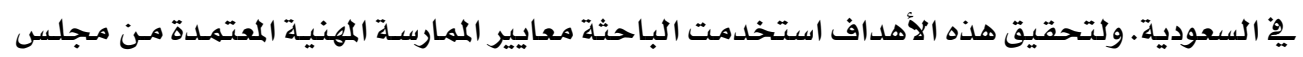

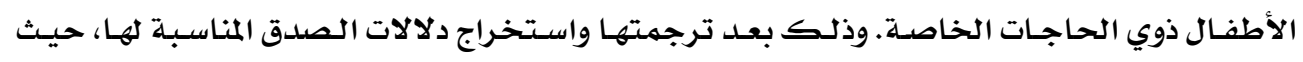

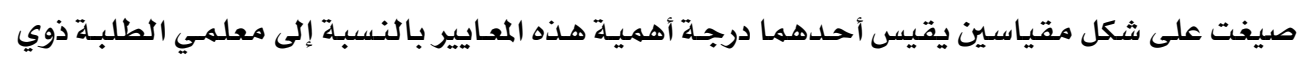

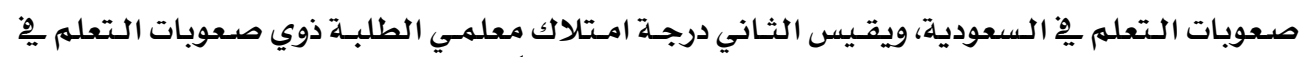

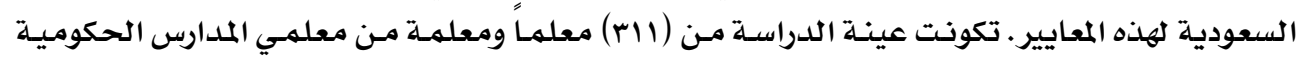

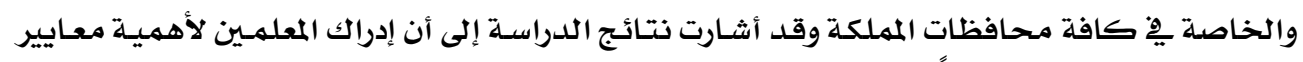

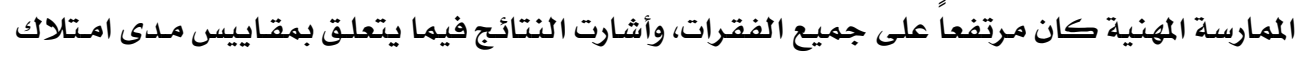

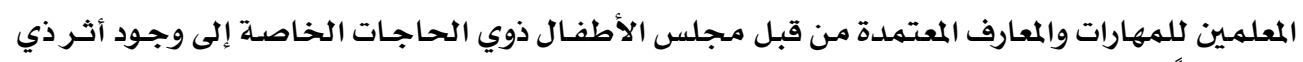

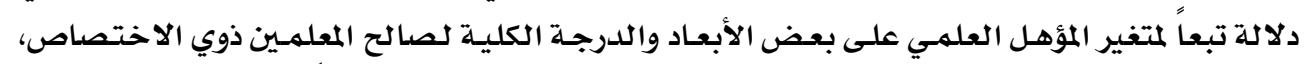

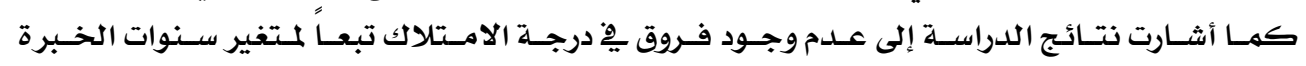
العامـة والخاصة.

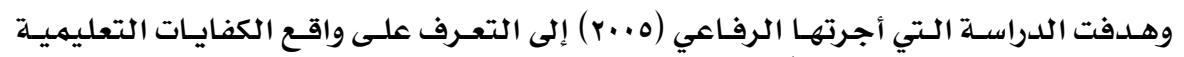

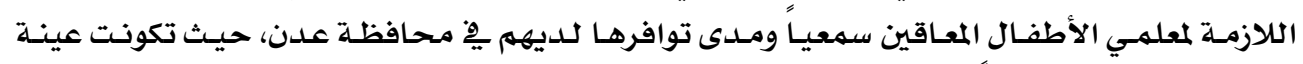

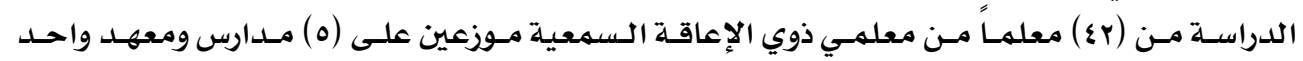

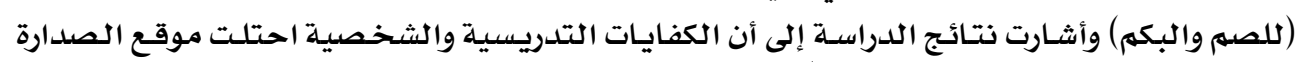

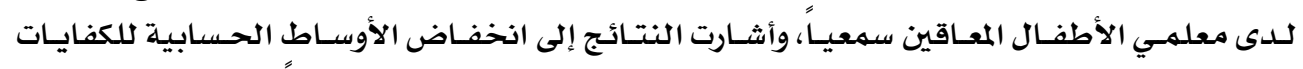

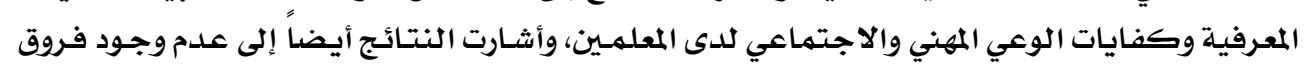

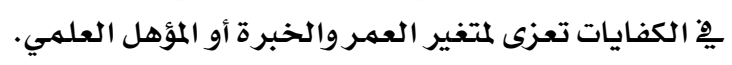

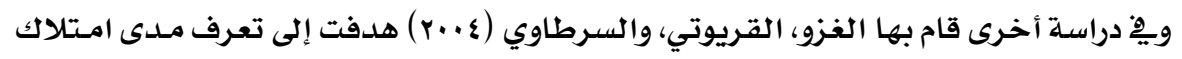

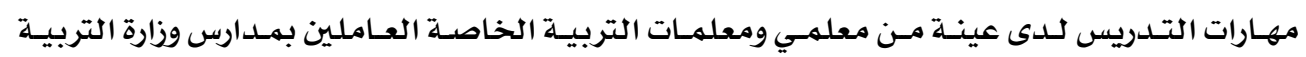

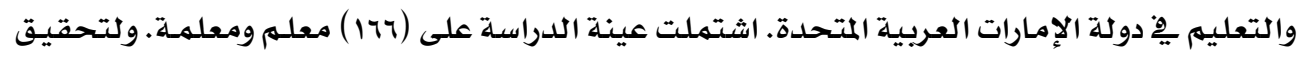

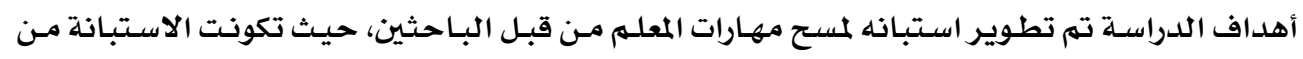

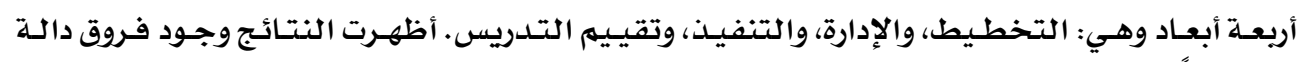

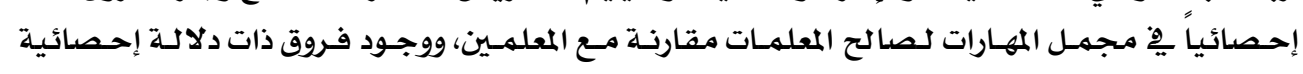

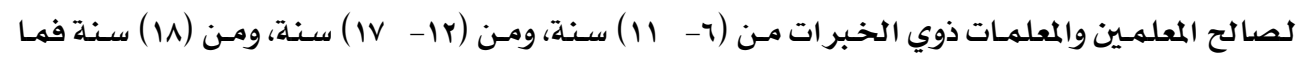


فوق. وكشفت النتائج أيضاً وجود أثر للتدريب على بعد الأداة الثالث وهو تنفيذ التدريس، ِِّ حين له

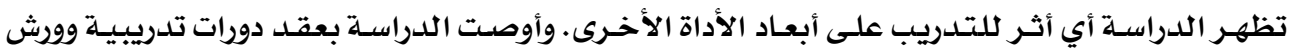

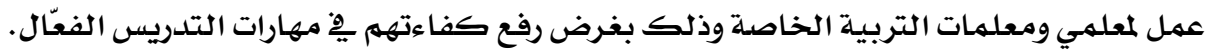

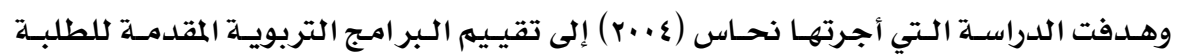

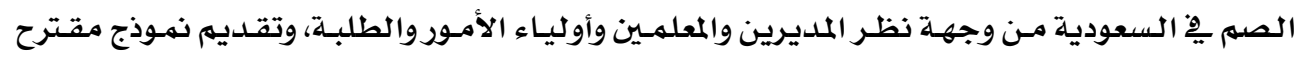

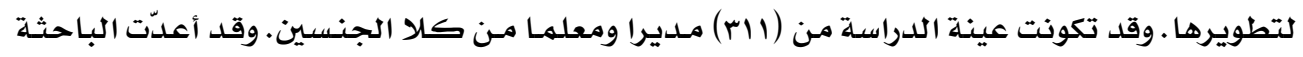

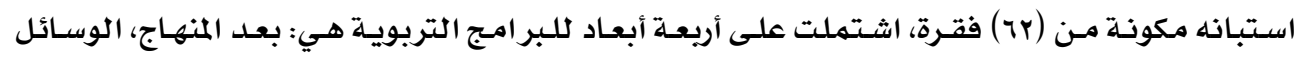

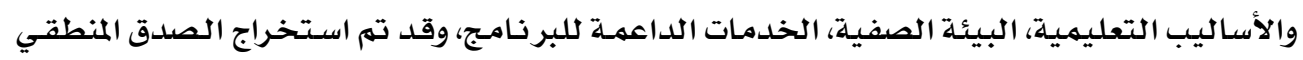

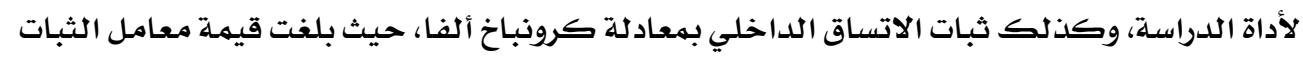

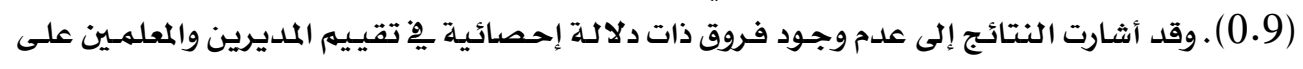

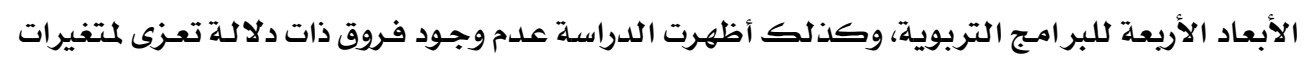

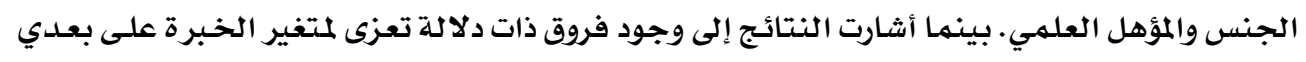

المنهاج والبيئة الصفية.

الدراسات الأجنبية:

وقام بويك (Bouck, 2014) بدراسـة هدفت إلى تقييم مـدى رضـا معلمي الطلبـة مـن ذوي

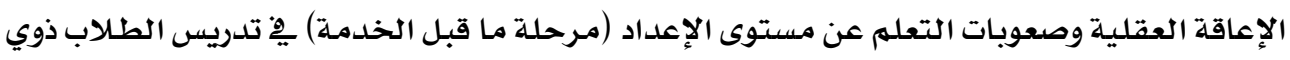

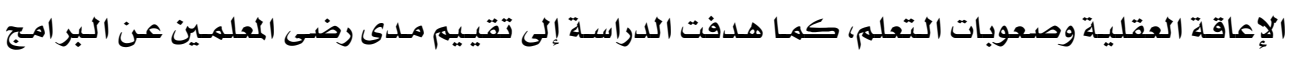

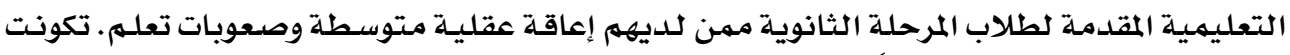

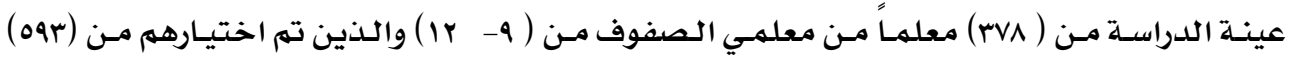

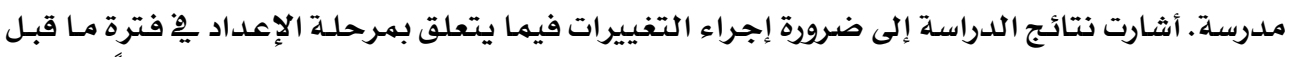

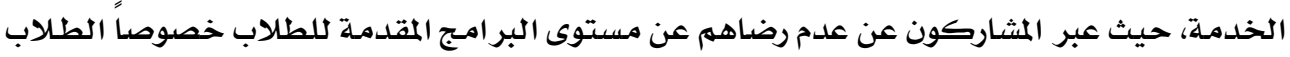

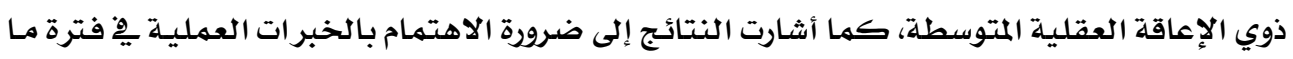

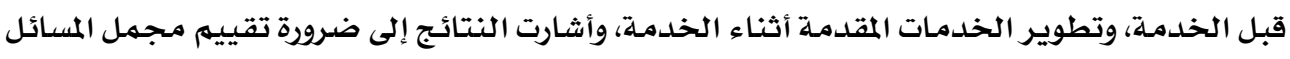

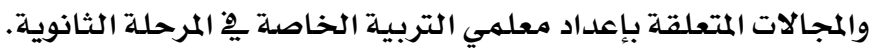

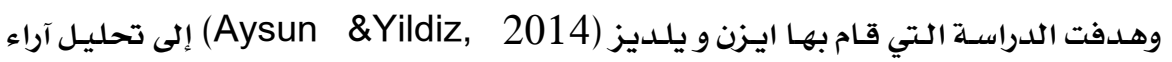

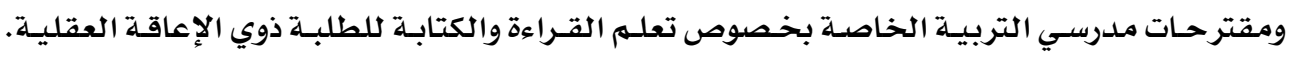

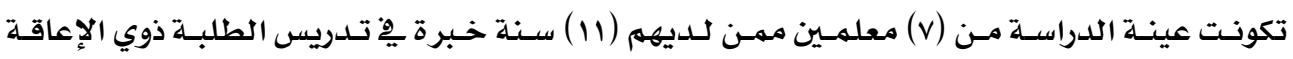

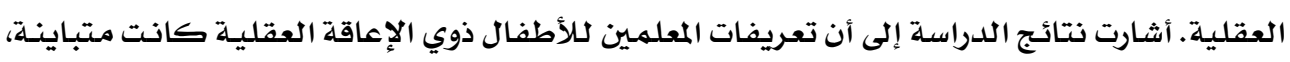

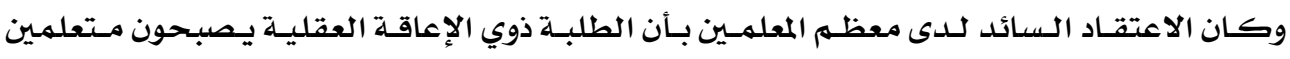

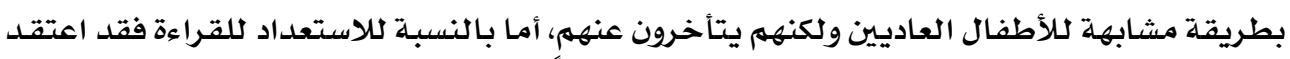

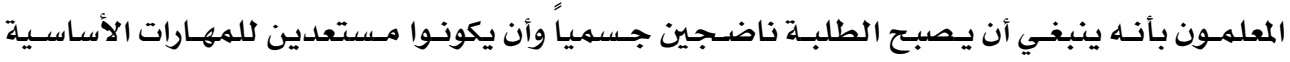

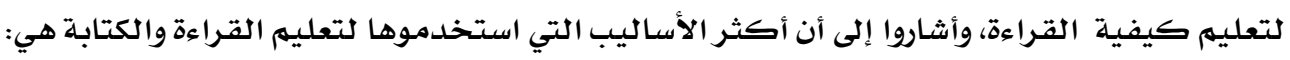




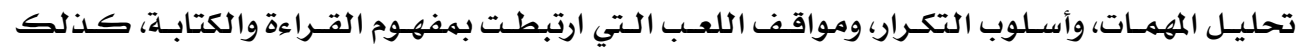

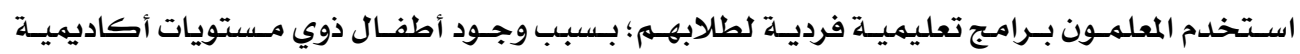

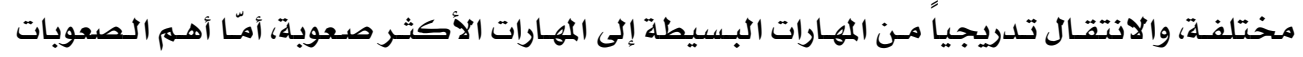

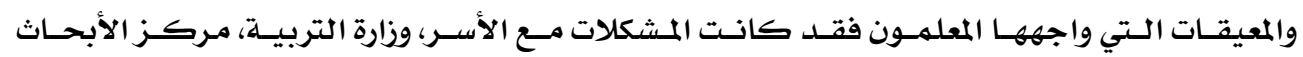
والجامعات، ومدراء المدارس.

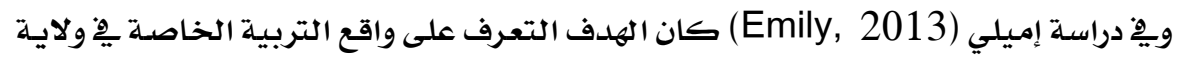

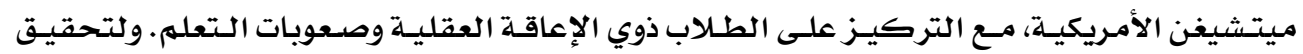

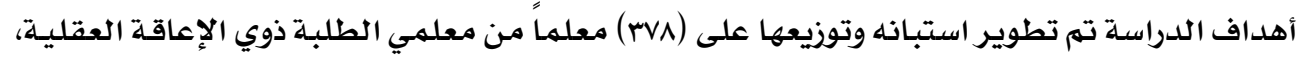

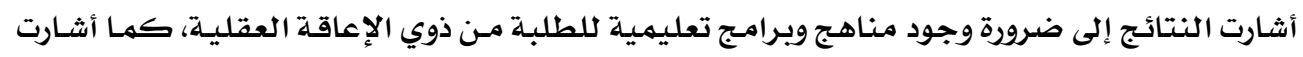

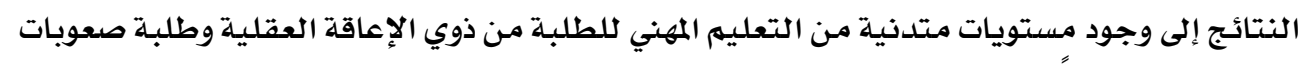

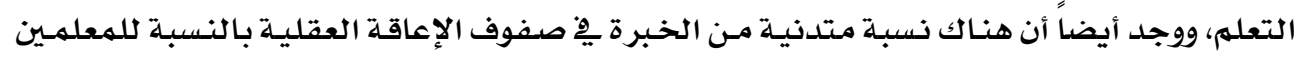

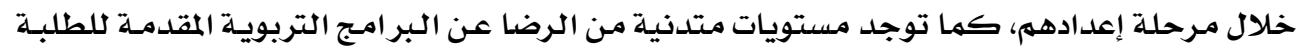

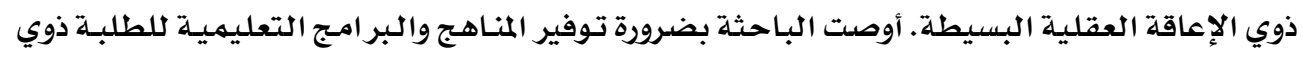

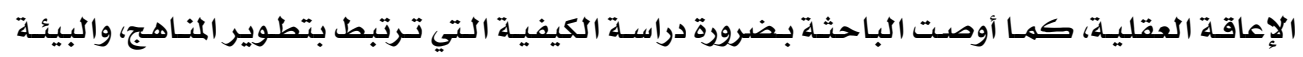

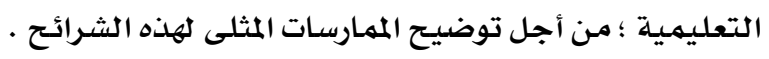

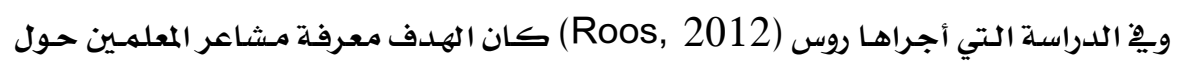

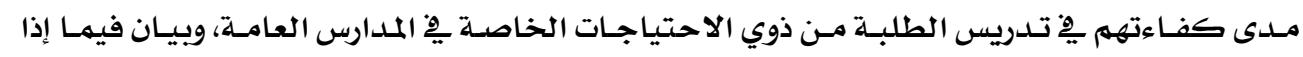

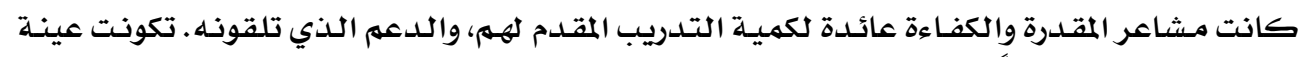

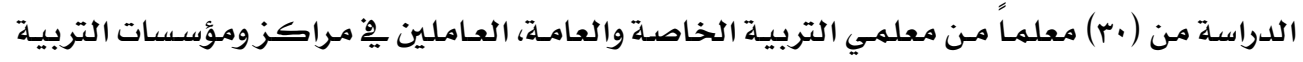

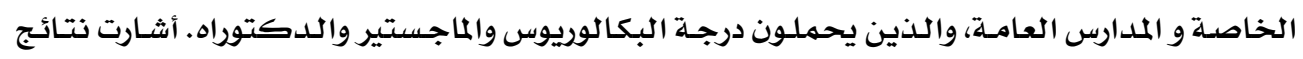

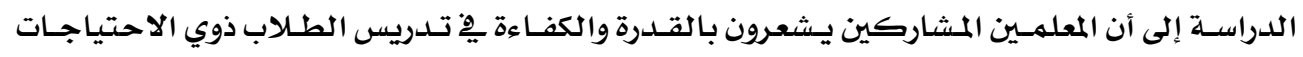

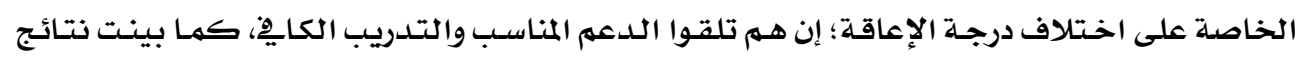

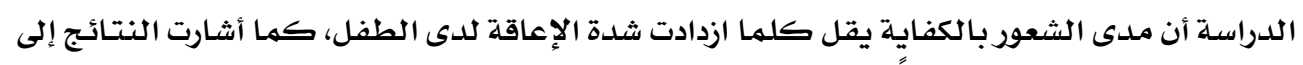

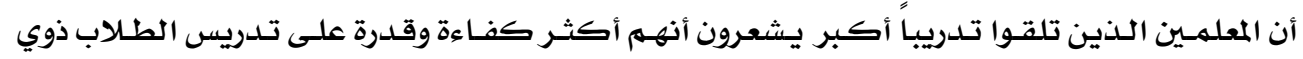
الاحتياجات الخاصة يِّ المدارس العامة.

هموأجرى كل مـن كارلسون، لي، وويستات (Carlson, Lee \& Westat, 2011)

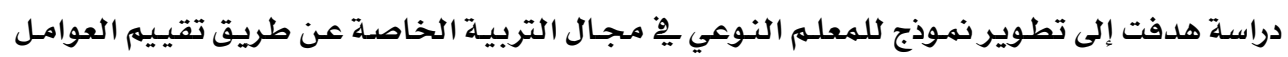

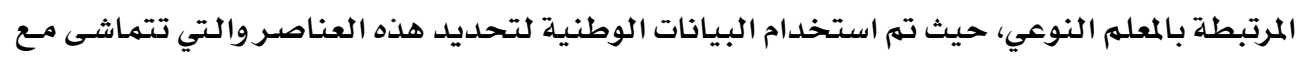

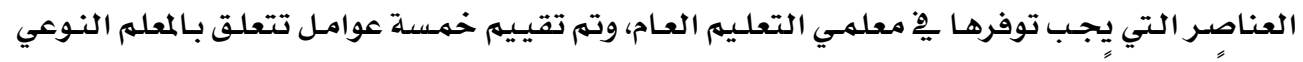

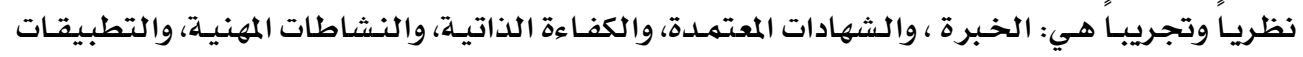

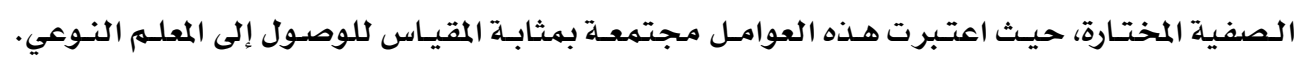

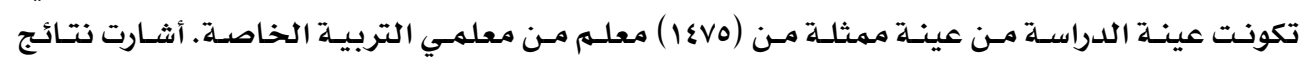




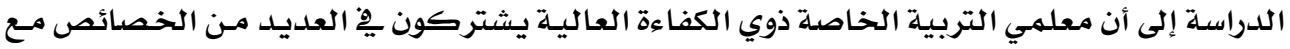

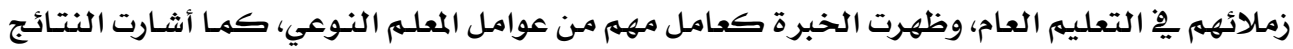

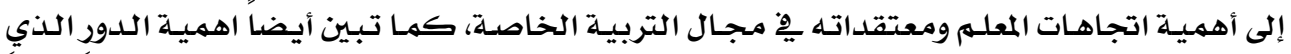

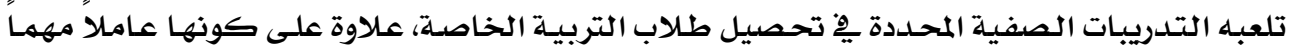

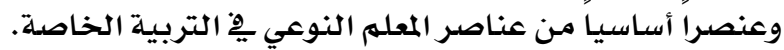

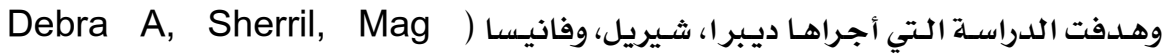
(\&Vanessa, 2011

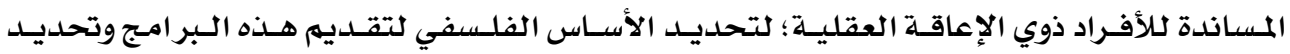

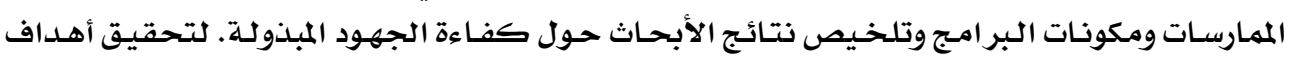

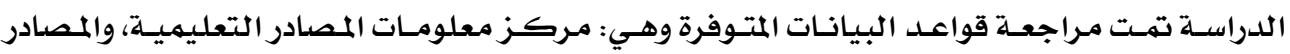

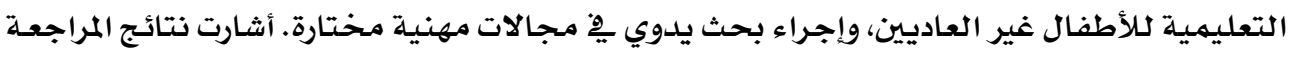

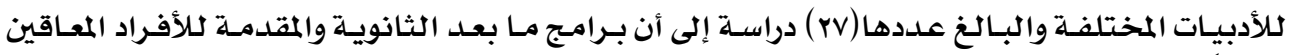

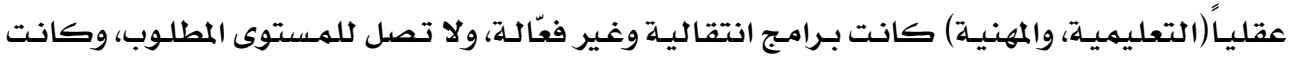

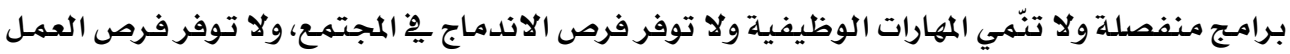
مدفوع الأجر.

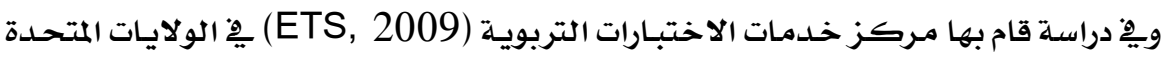

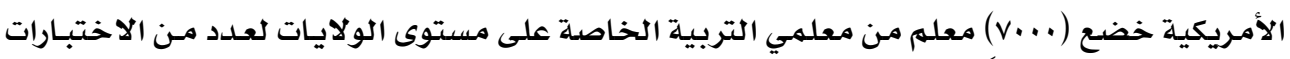

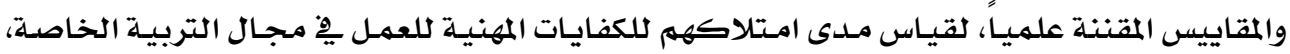

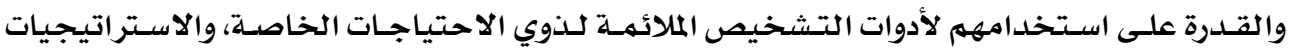

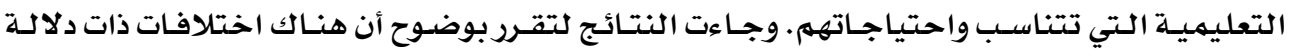

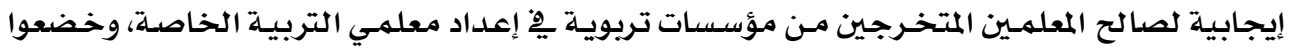

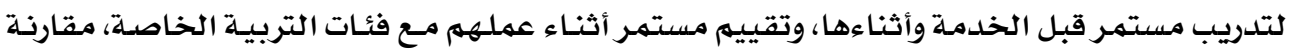

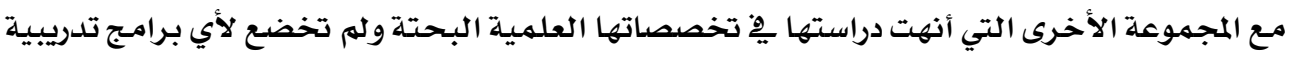

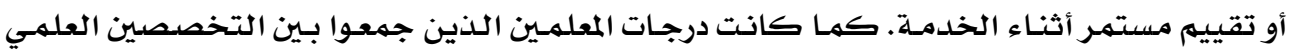

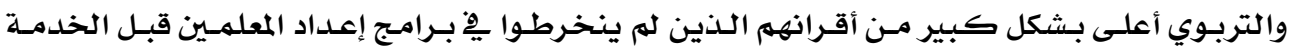

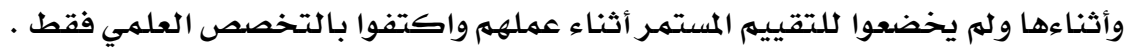
هدفت دراسة لي، كيه، وكانق (Lee,Kim \& Kang, 2008) إلى تقييم مستوى الكفايـة

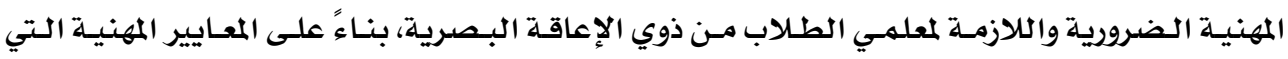

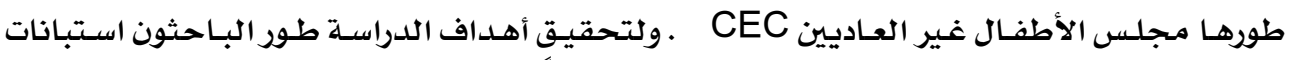

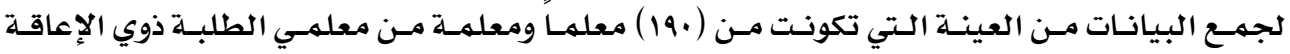

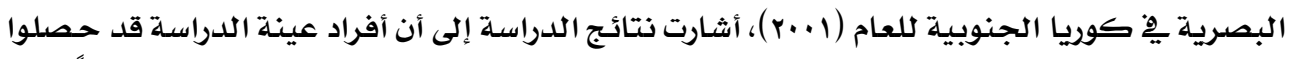

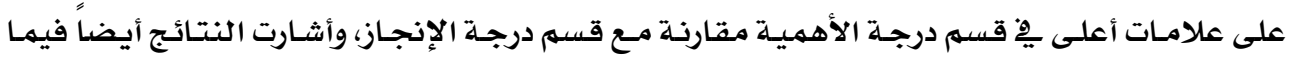




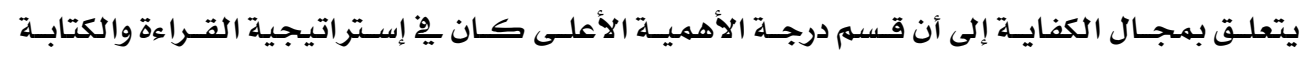

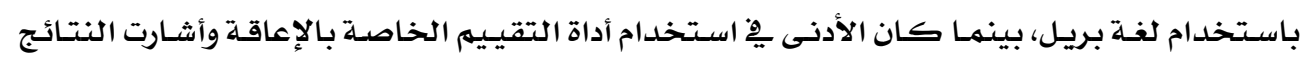

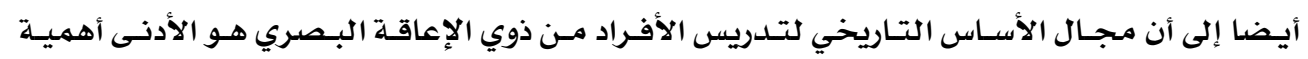

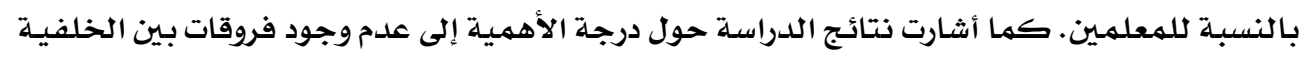

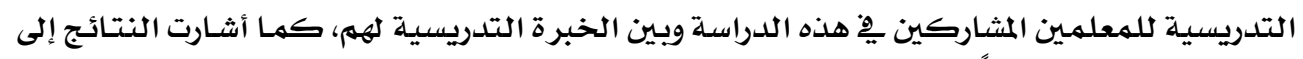

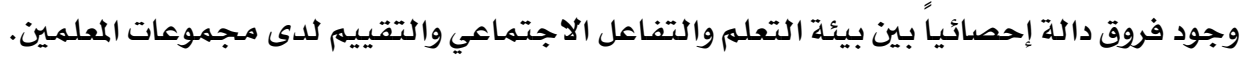

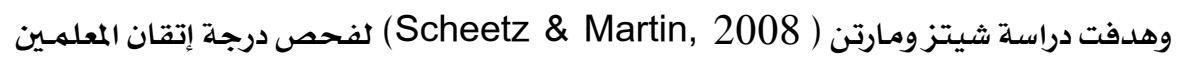

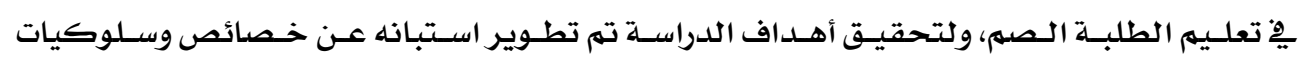

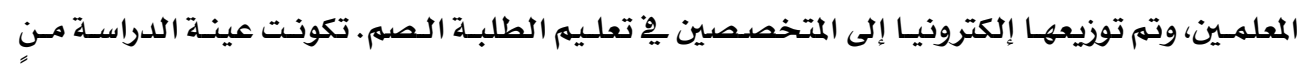

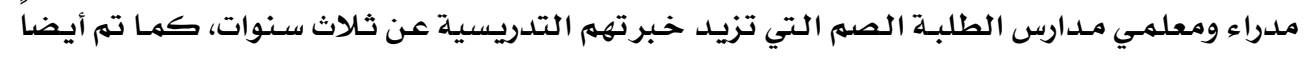

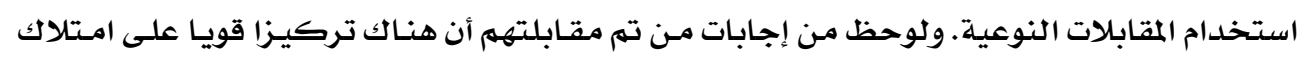

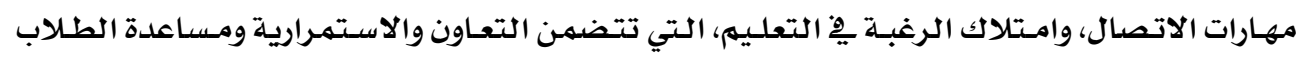

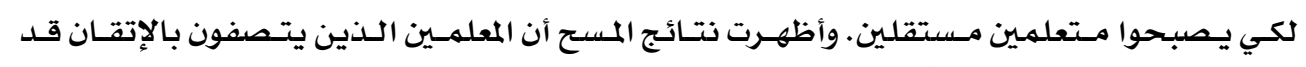

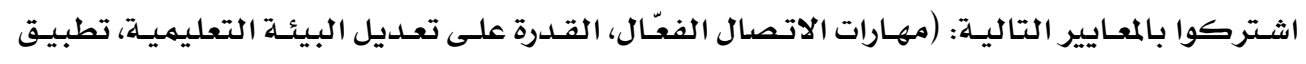

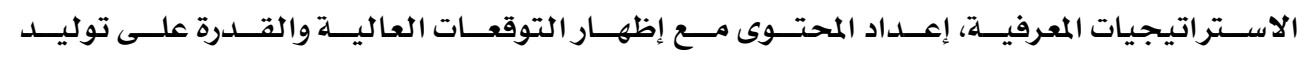

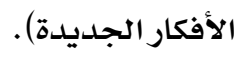

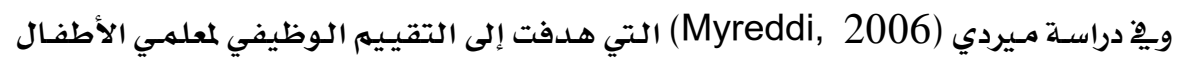

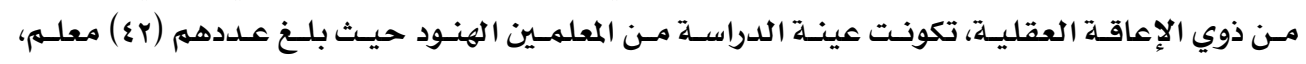

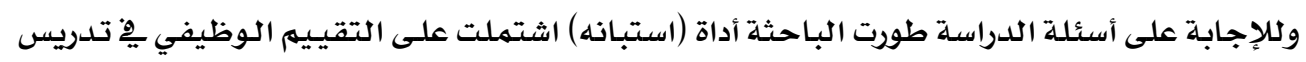

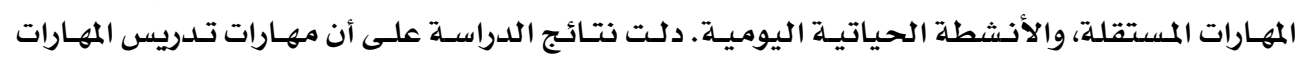

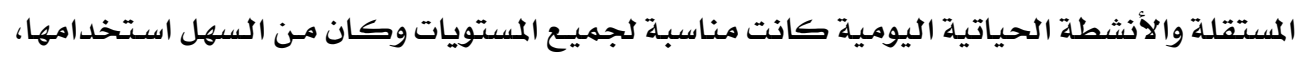

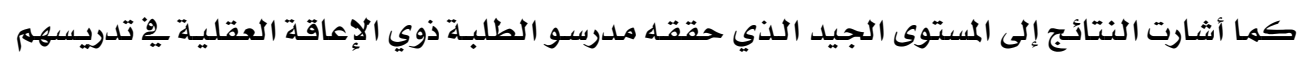
لتلك المهارات.

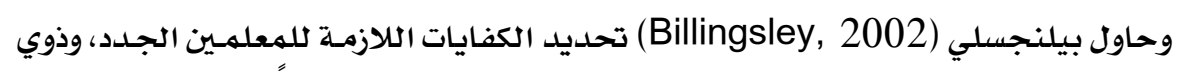

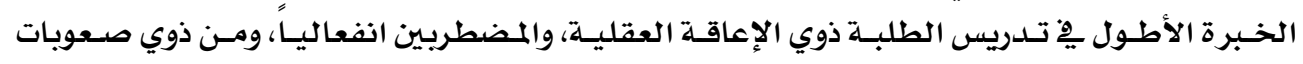

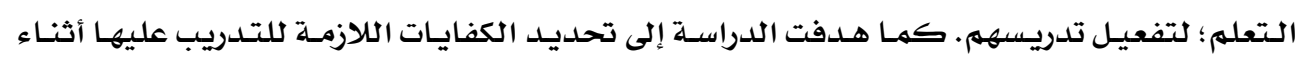

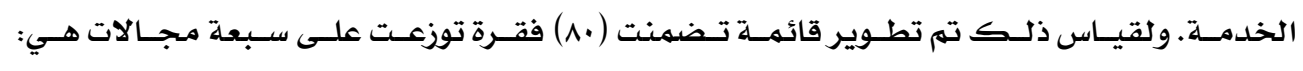

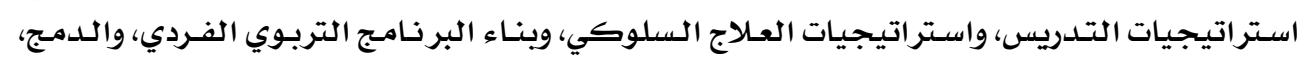

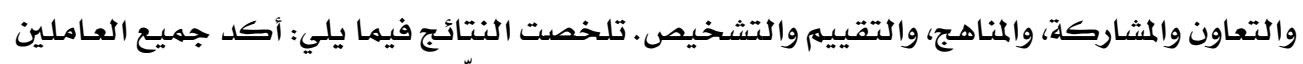

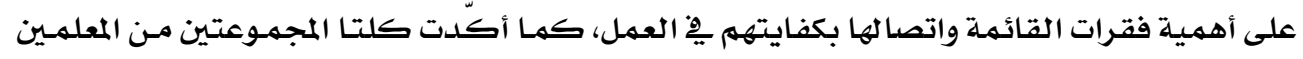

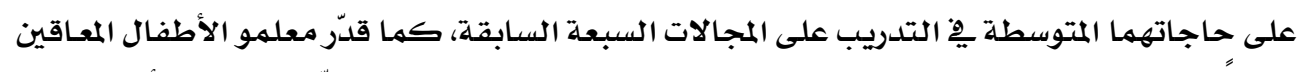
عقلياً الحاجة للتدريب على أساليب التدريس الخاصدة بطلابهم أكثر مما قدّرها معلمو الأطفال ذوي 


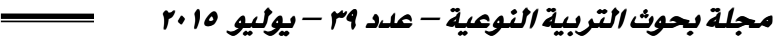

صعوبات التعلم، وأكد المعلمون من ذوي الخبرة الأطول ِِِ تدريس الأطفال المعاقين عقليـاً أن (ه) مـن

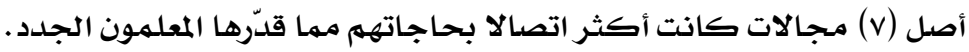

الطريقة والإجراءات

مجتمع الدراسة وأفرادها

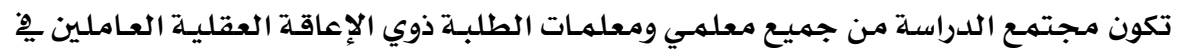

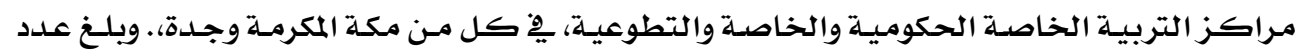

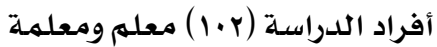

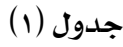

توزيـع أفراد مجتهـع الدراسـة حسب الجنس

\begin{tabular}{|c|c|c|}
\hline النسبة المئوية// & العدد & الجنس \\
\hline 5.9 & r & ذكر \\
\hline 94.1 & ruv & أنثى \\
\hline 100.0 & rq. & المجمهوع \\
\hline
\end{tabular}

ولتحقيق أهداف الدراسـة، ولإجابة عن سؤا لها تم اختيار العينة التي تكونت من (ץ ـ (1) معلم

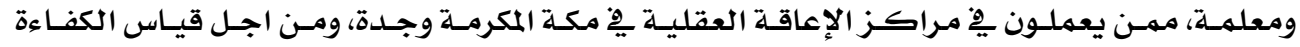

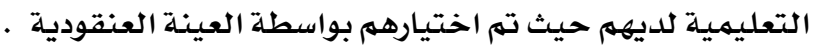

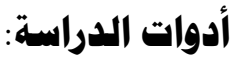
أولا: أداة الملاحظةلة المقياس)

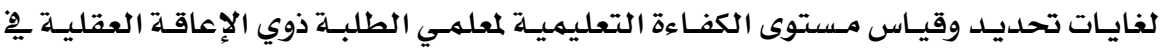

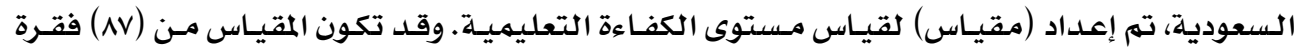
موزعة على أربعة أبعاد رئيسية وهي: • البعد الأول: التخطيط للتدريس وتصميمهه، ويقاس بالفقرات التالية (1- ب r r ).

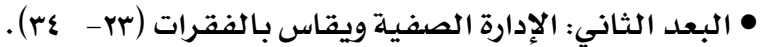

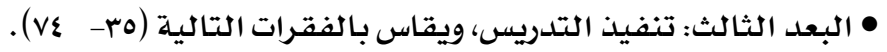

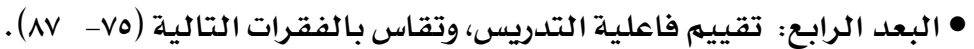
إجراءات إعداد الأداة:

تم إعداد وتطوير أداة الدراسة بالاعتماد على مراجعـة الأدب والدراسـات والمراجـع ذات الصلية.

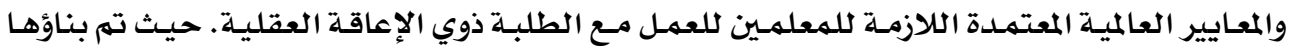
استنادا إلى ما يلي: 


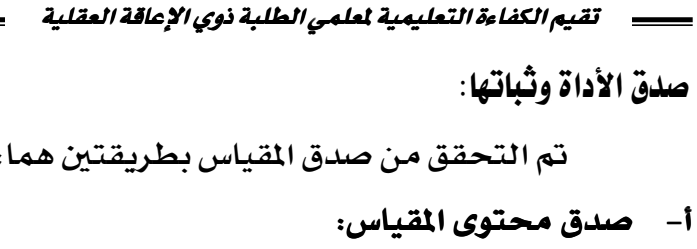

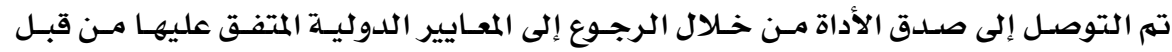

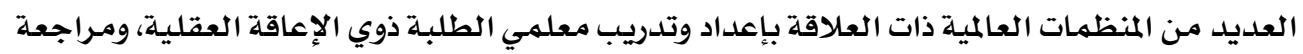

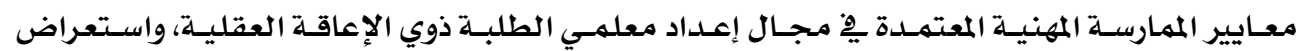

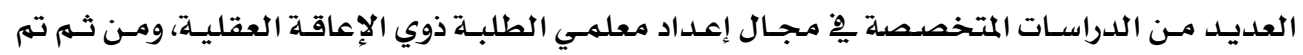

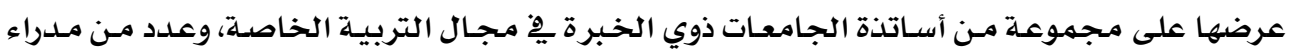

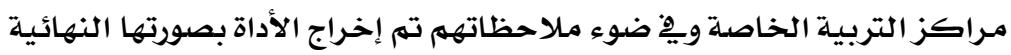
ب- ملدق البناء للمقياس

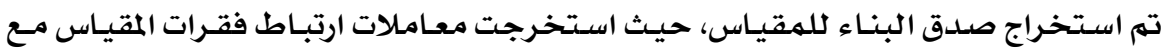

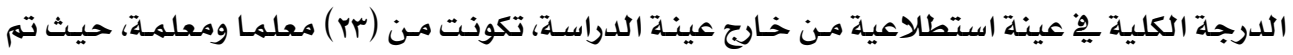

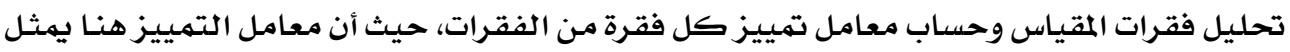

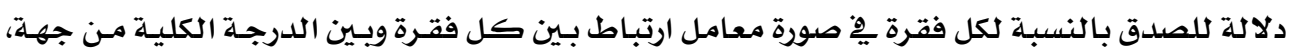

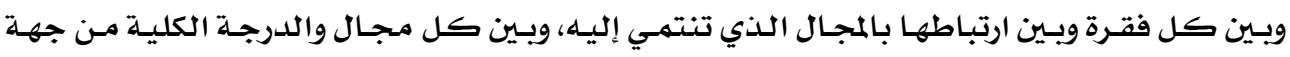

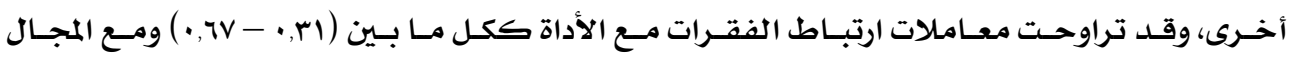

$(\cdot, V Y-\cdot, r)$

ثبات المقياس: استخرج ثبات المقياس بطريقتين هما:

أ- طريقة الاتساق الداخلي (كرونباخ ألفا)

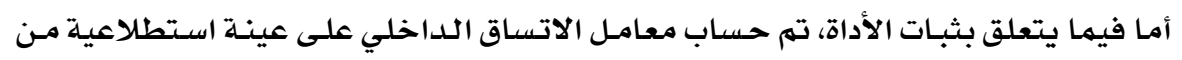

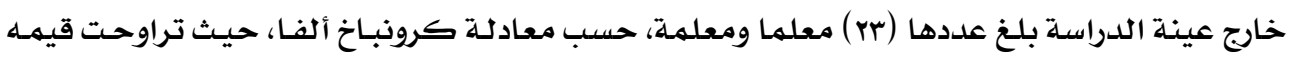

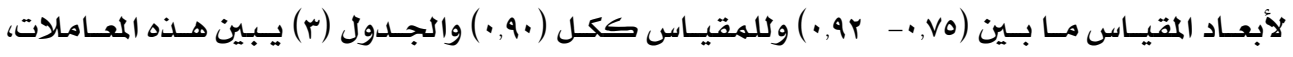

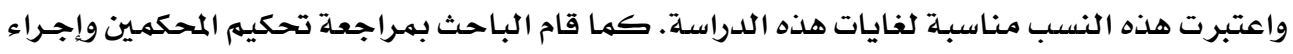

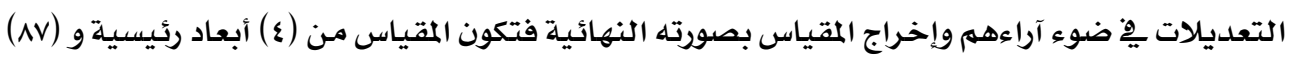
فقرة فرعية.

\section{ب- طريقة الاختبار إعادة الاختبار}

كما تم حساب الثبات عن طريق ثبات الإعادة ( معامل الاستقرار ) حيث تم تطبيق المقياس

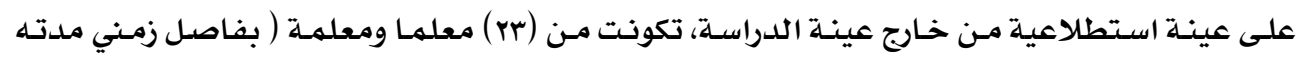

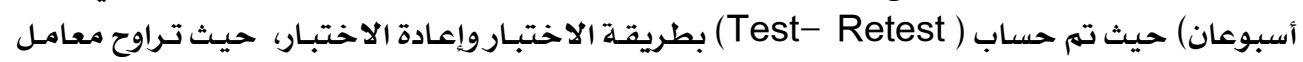


مجلة بحوث التربية النوعية - علد qج - يوليو 10 ب م

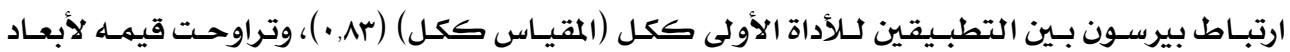

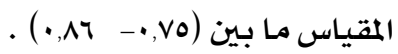

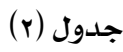

معامل ثبات الإعادة والاتساق الداخلي لكل بُعد من أبعاد المقياس وللمقياس ككل

\begin{tabular}{|c|c|c|}
\hline معامل ثبات الاتساق الداخلي & $\begin{array}{c}\text { معامل ثبات الإعادة } \\
\text { (بيرسون) } \\
\end{array}$ & 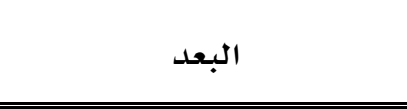 \\
\hline 0.92 & $\cdot, \wedge \cdot$ & التخطيط للتدريس وتصميمه \\
\hline 0.75 & •, vo & الإدارة الصفية \\
\hline 0.77 & $\cdot, \mathrm{va}$ & تنفيذ التدريس \\
\hline 0.89 & $\cdot, \wedge 7$ & تقييم فاعلية التدريس \\
\hline 0.90 & • & المقياس ككل \\
\hline
\end{tabular}

طريقة (همعايير) التصحيبح:

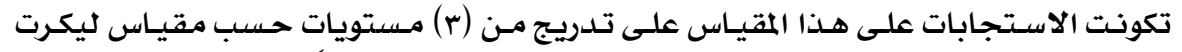

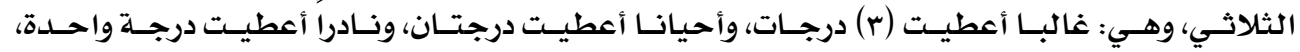

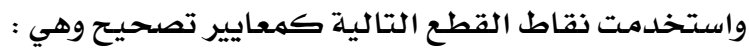

1- المتوسطات الحسابية التي تساوي أو تقل عن (1,TV) تعتبر متدنية.

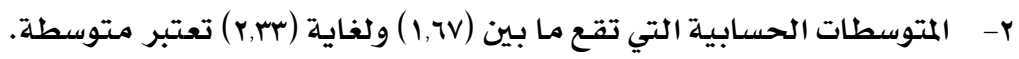

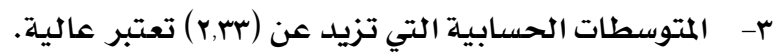

إجراءات الدراسة :

تمت عملية إعداد هذه الدراسـة بعدة مراحل تمثلت بها يلي:

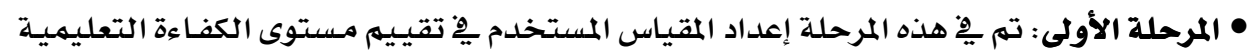

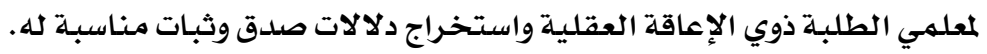

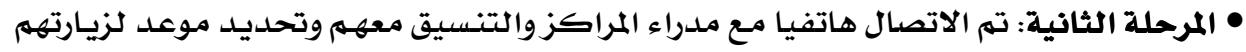

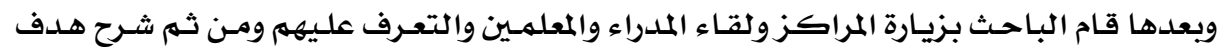
الدراسـة وأهميتهها.

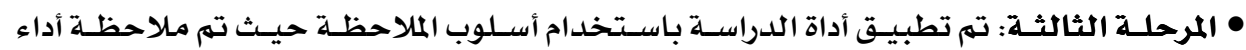
المعلمـين داخل الغرف الصفية وتقييم أدائهم باستخدل بام الأداة المطورة.

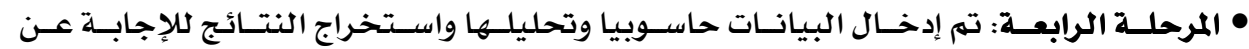

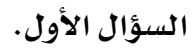
• المرحلة الخامسة : جمـع البيانات تمهيدا لإدخا لها حاسوبيا. 
استخدم المنهج المسحي بهدف تقييهم مستوى الكفاءة التعليميـة لمعلمـي الطلاب ذوي الإعاقـة

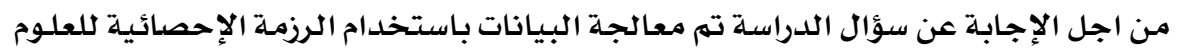

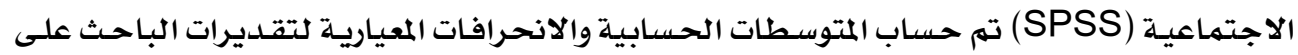

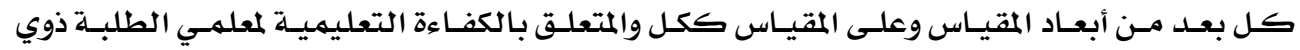
الإعاقة العقلية.

\section{مرض النتائج}

النتائج التي توصل إليها البحـث، والتي هـدفت إلى معرفة الكفاءة التعليميـة لمعلمـي الطلبـة

ذوي الإعاقة العقلية يِّ السعودية العنية

النتائج المتعلقة بالسؤال والذي ينص على: " ما مستوى الكفاءة التعليمية لمعلمي الطلبـة

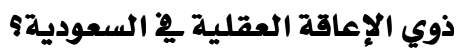

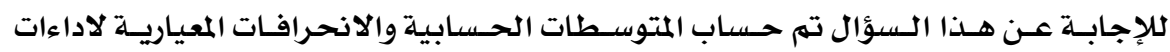

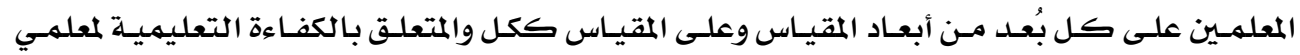

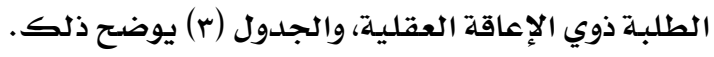

جدول(r)

المتوسطات الحسابية والانحرافات المعيارية لاداءات المعلمـين على كل بُعد من أبعاد المقياس وعلى المقياس ككل

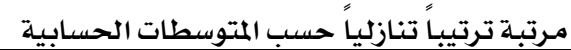

\begin{tabular}{|c|c|c|c|c|c|}
\hline درجـة & الانحراف المعياري & المستوسط * الحسب * & الرتبة & المجال & رقمال \\
\hline متوسطة & 0.41 & 1.92 & 1 & التخطيط للتدريس وتصميمـه & 1 \\
\hline متدنية & 0.34 & 1.54 & 2 & الإدارة الصفية & 2 \\
\hline متدنية & 0.19 & 1.33 & 4 & تنفيذ التدريس & 3 \\
\hline متدنية & 0.49 & 1.47 & 3 & تقييم فاعلية التدريس & 4 \\
\hline متدنيـة & 0.21 & 1.53 & \multicolumn{3}{|c|}{ المقياس ككل } \\
\hline
\end{tabular}

* الدرجة القصوى(r) 


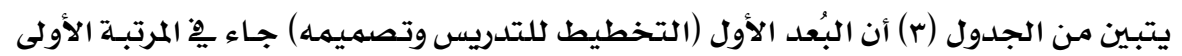

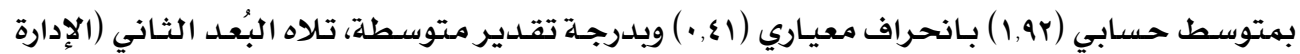

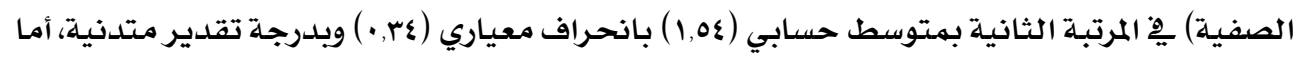

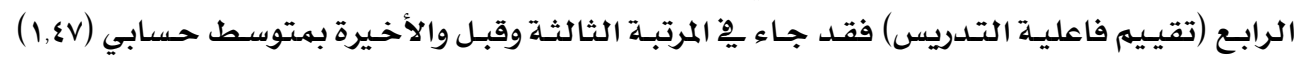

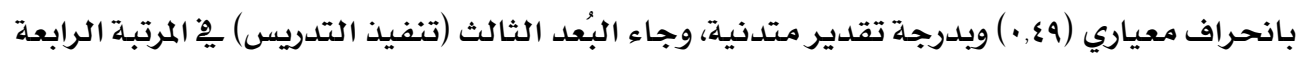

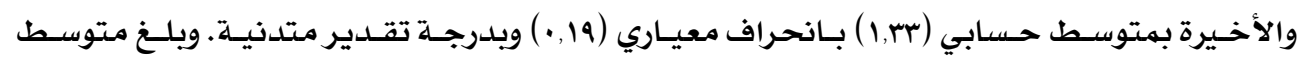

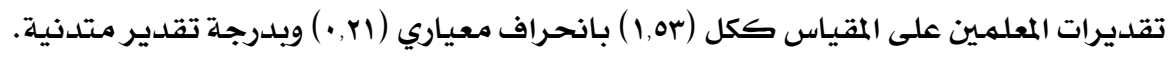

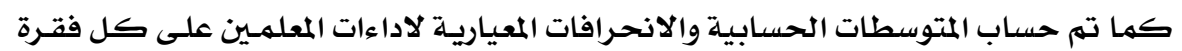

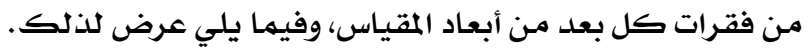




\section{أ- فيما يتعلق بفقرات البعد الأول (التخطيط للتدريس وتصميمه):}

جدول (๕)

المتوسطات الحسابية والانحرافات المعيارية لاداءات المعلمين على كل فقرة من فقرات البعد الأول (التخطيط

للتدريس وتصميمهه) مرتبة ترتيبا تنازليا حسب المتوسطات الحسئ الحسابية

\begin{tabular}{|c|c|c|c|c|c|}
\hline | درجة التقدير & الانحراف & | الحسابي * التوسط & الرتبة & 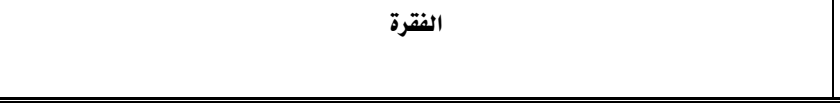 & رقم \\
\hline عالية & 0.73 & 2.56 & 1 & | يُحدّد مستوى الأداء الحالي للطلبة. & 1 \\
\hline عالية & 0.73 & 2.38 & 2 & ليصوغ أهداف الخطة التربوية الفردية بناءً على مستوى الأداء الحالي للطالب ذوي الإعاقة العقلية. & 16 \\
\hline عالية & 0.69 & 2.36 & 3 & | يلتزم المعلم بنقاط القوة والضعف لدى الطالب عند صياغة الأهداف التعليمية. & 3 \\
\hline 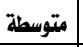 & 0.75 & 2.30 & 4 & | يُحدّد معايير النجاح في الأداء للأهداف التعليمية السنوية والأهداف قصيرة المدى. & 8 \\
\hline 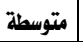 & 0.71 & 2.29 & 5 & | ليتزم المعلم بتنفيذ الخطة التزبوية الفردية . & 15 \\
\hline 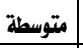 & 0.76 & 2.28 & 6 & | يُحدّد الفجوة بين مستوى الأداء الحالي للطلبة والأداء المتوقع الوصول إليه. & 2 \\
\hline 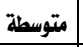 & 0.80 & 2.12 & 7 & | يُحدّد ظروف الأداء للأهداف التعليمية السنوية والأهداف قصيرة المدى. & 7 \\
\hline 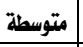 & 0.76 & 2.05 & 8 & |يصوغ الأهداف التعليمية السنوية والأهداف قصيرة المدى بطريقة إجرائية. & 6 \\
\hline | متوسطة & 0.67 & 2.03 & 9 & |يصوغ الأهداف التعليمية السنوية والأهداف قصيرة المدى بشكل متسلسل وتدريجي. & 5 \\
\hline 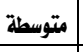 & 0.60 & 2.03 & 9 & | يتناسب محتوى الخطة التربوية الفردية التي يتم تطويرها واحتياجات الطلبة ذوي الإعاقة العقلية. & 14 \\
\hline 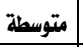 & 0.72 & 1.94 & 11 & |يراعي واقعية الخطة وموضوعيتها وقابليتها للتنفيذ. & 9 \\
\hline 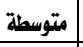 & 0.77 & 1.93 & 12 & [يراعي عامل المرونة بجيث يمكن تعديل الخطة حسب الجاجات الفردية لكل طالب. & 10 \\
\hline 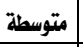 & 0.61 & 1.87 & 13 & | يصمى برنامج تربوي يتناسب مع الحاجات التعليمية للطالب. & 12 \\
\hline 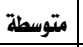 & 0.66 & 1.86 & 14 & | يستخدم الوسائل والمواد التعليمية المناسبة. & 21 \\
\hline متوسطة & 0.77 & 1.76 & 15 & | ينوع في الأهداف التعليمية بحيث تشمل مثلاً: أهداف أهداف معرفية وانفعالية، وحس حركية ولفوية. & 11 \\
\hline | متوسطة | - متية & 0.59 & 1.75 & 16 & ليستخدم المعلومات والبيانات المتوفرة عن أداء الطلبة للتخطيط للتعليم . & 22 \\
\hline 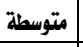 & 0.75 & 1.72 & 17 & |يقتمد جدولاً محدداً للنشاطات الأكاديمية وغير الأكاديمية اليومية & 20 \\
\hline 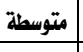 & 0.63 & 1.70 & 18 & |يراعي ارتباط الأهداف في الخطة التربوية الفردية بالأنشطة الحياتية اليومية للطلبة ذوي الإعاقة العقلية. & 13 \\
\hline 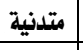 & 0.63 & 1.62 & 19 & |يضع خطة سنوية وخطة فصلية وخطة شهرية لبرنامج تعليم وتدريب الطلبة. & 4 \\
\hline 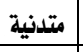 & 0.49 & 1.24 & 20 & | يتعاون مع أعضاء الفريق التربوي عند التخطيط لبرامج الطلبة. & 19 \\
\hline 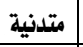 & 0.51 & 1.23 & 21 & ليضع خطة لإدارة وضبط وتسجيل السلوك والأداء. & 17 \\
\hline 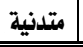 & 0.39 & 1.13 & 22 & | يعتمد دليلا للعلم يساعده في تعليم كل درس أو مهارة. & 18 \\
\hline
\end{tabular}

(r) (الدرجة القصوى)

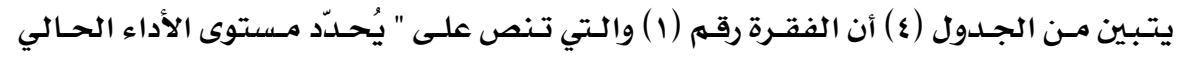

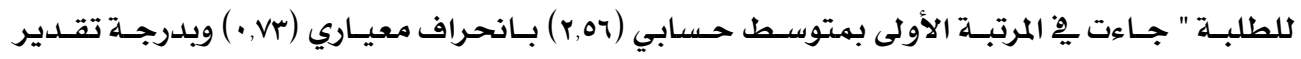




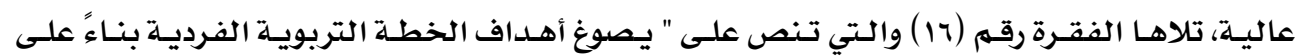

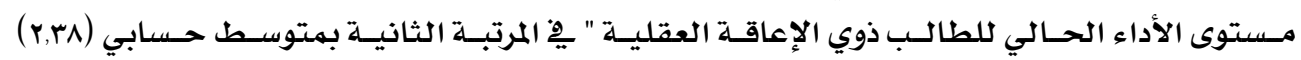

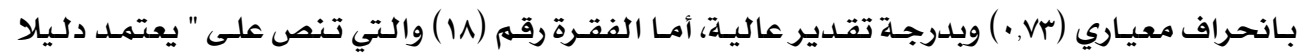

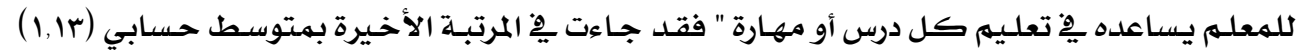

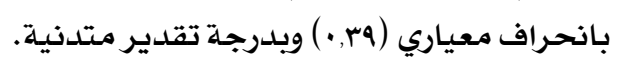
ب- فيما يتعلق بفقرات البعد الثاني (الإدارة الصفية): جدول(0)

المتوسطات الحسابية والانحرافات المعيارية لاداءات المعلمين على كل فقرة من فقرات البعد الثاني (الإدارة

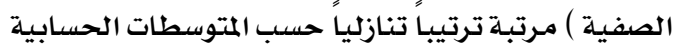

\begin{tabular}{|c|c|c|c|c|c|}
\hline التقدير & |الانحراف| & 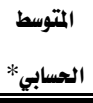 & الرتبة & الفقرة & رقم \\
\hline متوسطة & 0.77 & 1.87 & 1 & 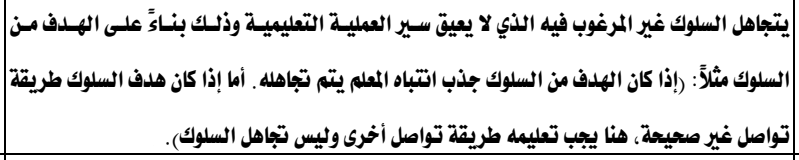 & 32 \\
\hline 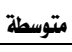 & 0.78 & 1.84 & 2 & | يستخدم التعزيز الايجابي بطريقة مناسبة لتدعيم السلوك المرغوب فيه & 31 \\
\hline 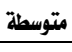 & 0.74 & 1.67 & 3 & | يتعامل مع مشكلات الطلبة الآنية والطارئة أثناء التدريس بشكل مناسب. & 34 \\
\hline 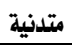 & 0.77 & 1.65 & 4 & |يستخدم أساليب مناسبة لخفض الاستجابات التي تعيق سير العملية التعليمية(أساليب تعديل السلوك). & 33 \\
\hline 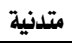 & 0.73 & 1.61 & 5 & | يحرص على أن تخلو الفرفة الصفية من الأدوات والأشياء التي قد تشكل خطراً على حياة الطفل. & 24 \\
\hline 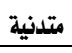 & 0.65 & 1.60 & 6 & | يُوضّح قواعد السلوك الصفي(السلوك المقبول وغير المقبول). & 27 \\
\hline 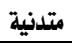 & 0.64 & 1.45 & 7 & ليُوفر بيئة تعليمية صفية مريحة ومناسبة ( مثلا: الإذارة، التهوية، المساحة). & 23 \\
\hline 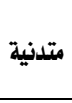 & 0.64 & 1.44 & 7 & 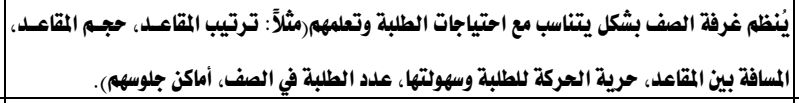 & 26 \\
\hline 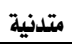 & 0.57 & 1.41 & 9 & ليُعدّ ترتيب المقاعد حسب الأنشطة الصفية وملى مناسبتها لطبيعة الأهداف. & 25 \\
\hline 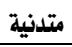 & 0.59 & 1.36 & 10 & |يعدّل المعلم خطة تعديل السلوك حسب الحاجة. & 30 \\
\hline 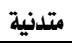 & 0.56 & 1.29 & 11 & يعرّف المعلم السلوك المستهلف بدقة ووضوح قبل تنفيذ خطة تعديل السلوك. & 28 \\
\hline 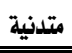 & 0.52 & 1.23 & 12 & |يقوم بهلاحظة وتسجيل السلوك المراد تعديله. & 29 \\
\hline
\end{tabular}

$$
\text { * (r) الدرجة القصوى }
$$

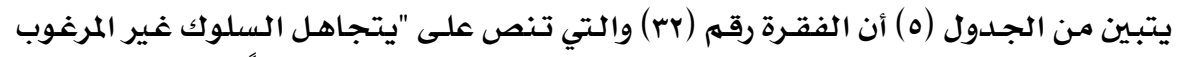

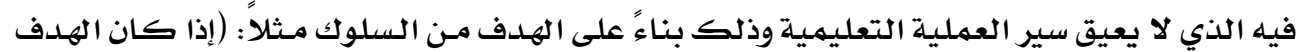

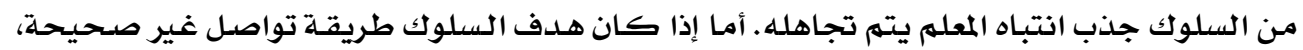

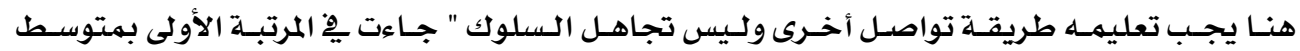




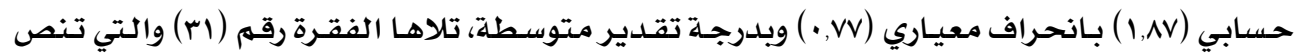

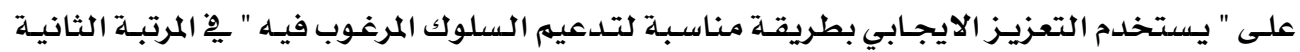

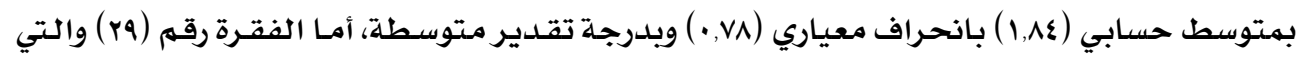

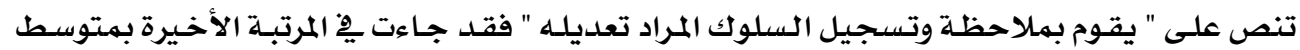

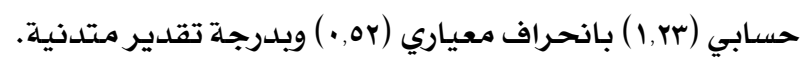

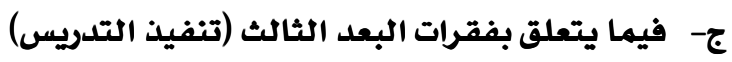

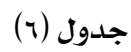

المتوسطات الحسابية والانحرافات المعيارية لاداءات المعلمين على كل فقرة من فقرات البعد الثالث (تنفيذ

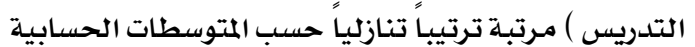

\begin{tabular}{|c|c|c|c|c|c|}
\hline التقدير & الانحراف & | الحسابي * & 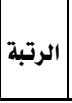 & 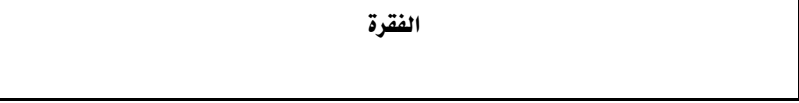 & رقم \\
\hline متوسطة & 0.87 & 2.11 & 1 & يعمل بشكل فردي مع الطلبة عند الحاجة لذنك. & 73 \\
\hline متوسطة & 0.78 & 1.74 & 2 & يُوفر الآليات الللازمة للحصول على المساعدة التي قد يحتاجها الطلبة. & 74 \\
\hline متوسطة & 0.79 & 1.68 & 3 & يُصحح أخطاء الطلبة بشكل فوري(في نفس الوقت). & 54 \\
\hline متوسطة & 0.72 & 1.67 & 4 & يُقيتيّم باستمرار ملدى التقدم في أداء الطلبة. & 72 \\
\hline 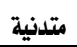 & 0.75 & 1.58 & 5 & يُقدّم أمثلة عديدة بشكل دوري للمساعدة على توضيح الفكرة. & 50 \\
\hline 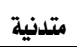 & 0.75 & 1.54 & 6 & يجذب اتتباه الطلبة عند تنفيذ المهمة التعليمية(مثال: أن يشير المعلم بيده للطلبة، يصلر صوت، حركة). & 40 \\
\hline 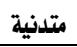 & 0.75 & 1.53 & 7 & يراعي وصول الطالب إلى درجة الإتقان في كل خطوة. & 53 \\
\hline 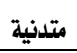 & 0.73 & 1.53 & 8 & يُقدّم مراجعة تراكمية للمفاهيم الجديلدة التي تم تعليمها. & 55 \\
\hline متدنية & 0.67 & 1.46 & 9 & يُعدِّل محتوى المناهج بما يتناسب مع الأهداف التعليمية. & 49 \\
\hline متدنية & 0.73 & 1.45 & 10 & يُحدّد أهداف الحصة بما يتناسب مع الأهداف السنوية والأهداف قصيرة الملدى. & 35 \\
\hline متدنية & 0.69 & 1.40 & 11 & | يُحدّد أهداف الحصة بطريقة قابلة للقياس. & 36 \\
\hline متدنية & 0.68 & 1.40 & 11 & يستخدم أسلوب التلقين عند الحاجة. & 69 \\
\hline متدنية & 0.68 & 1.38 & 13 & يستخدم لفة سليمة تتناسب ومستوى الطلبة. & 41 \\
\hline متدنية & 0.59 & 1.36 & 14 & يلدّعم التدريس بتدريبات ملائمة للطلبة. & 51 \\
\hline 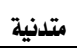 & 0.59 & 1.34 & 15 & يربط مادة الدرس بالحياة العملية واليومية. & 52 \\
\hline 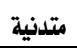 & 0.62 & 1.33 & 16 & يستخدم أسلوب تحليل المهمات عند الحاجة. & 65 \\
\hline 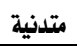 & 0.63 & 1.32 & 17 & يستخدم الوسائل والأدوات والمواد التعليمية المناسبة. & 38 \\
\hline 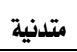 & 0.56 & 1.31 & 18 & ي يُقيّيم الأهداف الموضوعة ضمن الحصة. & 39 \\
\hline 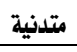 & 0.64 & 1.31 & 18 & يحلل المهمات والمهارات التعليمية بشكل مناسب قبل البدى بالتدريس. & 45 \\
\hline 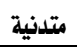 & 0.61 & 1.30 & 20 & يستخدم حواس الطفل المختلفة في عمليات التدريب. & 61 \\
\hline
\end{tabular}




\begin{tabular}{|c|c|c|c|c|c|}
\hline التقدير & |الانعراف & | الحسابي * & | الرتبة & 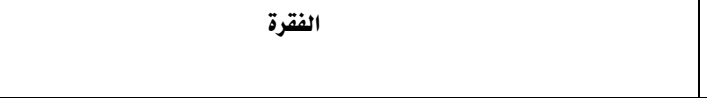 & |الفقرة \\
\hline 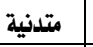 & 0.61 & 1.29 & 21 & | يستخدم الوسائل البصرية والوسائل السمعية (الصور والرسومات) في توضيح اللدروس. & 66 \\
\hline 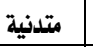 & 0.57 & 1.28 & 22 & | يستخدم أنشطة متنوعة لتدريس المحتوى التعليمي. & 48 \\
\hline 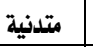 & 0.57 & 1.27 & 23 & | يستخدم التواصل اللفظي وغير اللفظي لاستثارة اتتباه الطلبة. & 42 \\
\hline 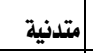 & 0.55 & 1.27 & 23 & | يربط الدرس الحالي باللدروس السابقة . & 44 \\
\hline 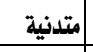 & 0.57 & 1.25 & 25 & | ينتقل تدريجيا من المهارات البسيطة إلى المهارات الأكثر تعقيلداً. & 46 \\
\hline 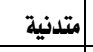 & 0.54 & 1.22 & 26 & | يُحدّد معايير انجاز أهداف الحصة. & 37 \\
\hline 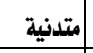 & 0.42 & 1.20 & 27 & | يحافظ على مستوى ملائم من الدافية لدى الطلبة. & 63 \\
\hline 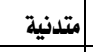 & 0.50 & 1.19 & 28 & | يُعيئ الطلبة في بداية الحصة للدرس الجديد. & 43 \\
\hline 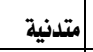 & 0.48 & 1.19 & 28 & |يُقسّم الطلبة إلى مجموعات صفيرة، تتعاون معا للوصول إلى الهلدف المطلوب. & 70 \\
\hline 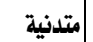 & 0.45 & 1.18 & 30 & | يستخدم أسلوب النمذجة عند الحاجة. & 67 \\
\hline 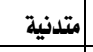 & 0.47 & 1.17 & 31 & | يُقلل تدخله تدريجيا لتعليم الطلبة الاستقلالية. & 56 \\
\hline 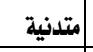 & 0.38 & 1.15 & 32 & | يستثمر الوقت المخصص للدرس بفاعليّة. & 64 \\
\hline 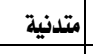 & 0.45 & 1.14 & 33 & | يُعدّل من السرعة في تقديم المحتوى الدراسي. & 59 \\
\hline 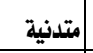 & 0.37 & 1.14 & 33 & | يستخدم المجسّمات في توضيح الدروس. & 68 \\
\hline 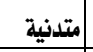 & 0.41 & 1.13 & 35 & | ل يستخدم الحاسوب في تعليم اللدرس. & 7 \\
\hline 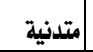 & 0.39 & 1.10 & 36 & | يقيم المعلم الأنشطة المستخدمة لتدريس المحتوى التعليي. & 47 \\
\hline 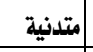 & 0.39 & 1.10 & 36 & | ليزود الطلبة بتفذية راجعة فورية متكررة. & 57 \\
\hline 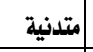 & 0.30 & 1.08 & 38 & | ليُوفر التعليم الإضافي للطلبة (أثناء الدوام الملدرسي، أو بعد الدوام المدرسي). & 60 \\
\hline 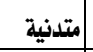 & 0.26 & 1.05 & 39 & |يشجع الطلبة الذين يستطيعون أداء المهمات بطريقة مقبولة على تدريب أقرانهم المعوقين. & 62 \\
\hline 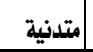 & 0.20 & 1.04 & 40 & | ايراعي الفروق الفردية في التدريس. & 58 \\
\hline
\end{tabular}

$$
\text { * (r) الدرجة القصوى) }
$$

يتبـين مـن الجدول (7) أن الفقرة رقم (Vr) والـتي تـنص على " يعهـل بشكل فردي مـع الطلبـة

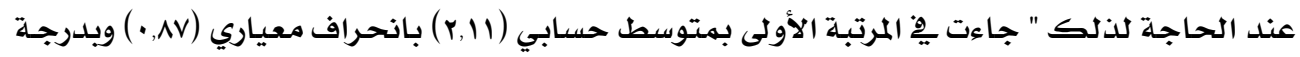
تقدير متتوسطة، تلاها الفقرة رقم (v) والتي تنص على " يُوفر الآليات اللازمسة للحصول على المسـاعدة

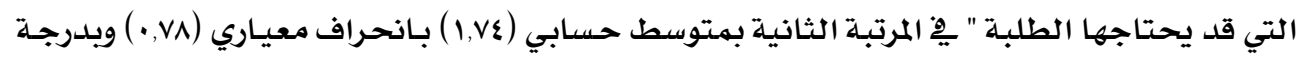

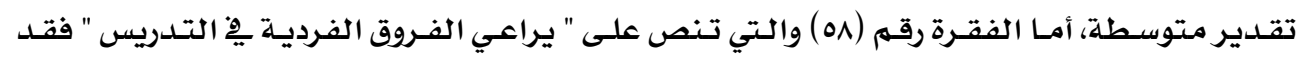

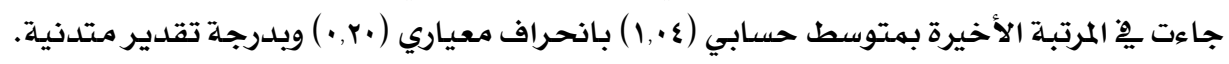




\section{د- فيما يتعلق بفقرات البعد الرابع (تقييم فاعلية التدريس)}

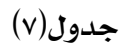

المتوسطات الحسابية والانحرافات المعيارية لاداءات المعلمين على كل فقرة من فقرات البعد الرابع (تقييم

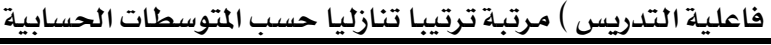

\begin{tabular}{|c|c|c|c|c|c|}
\hline |درجة & الانحراف & * الحتوسط & 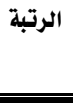 & 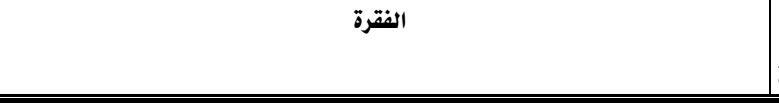 & رقم \\
\hline 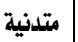 & 0.82 & 1.62 & 1 & | يُطور أدوات مناسبة لتقويم تعلم الطلبة. & 78 \\
\hline 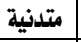 & 0.83 & 1.61 & 2 & | يُفسر تتائج الاختبارات التي تطبق على الطالب. & 80 \\
\hline 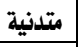 & 0.82 & 1.56 & 3 & | يستخدم سجلاً تراكياً لرصد تقدّم الطالب في مهارات التدريس. & 86 \\
\hline 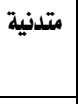 & 0.77 & 1.54 & 4 & | لتطبق أنواعا مختلفة من الاختبارات الخاصة بالطلبة ذوي الإعاقة العقلية(الاختبارات الخاصة بعملية & 79 \\
\hline 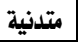 & 0.83 & 1.53 & 5 & ليُقيّيّم الأهداف السنوية والأهداف قصيرة المدى الموجودة في الخطة. & 84 \\
\hline 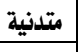 & 0.82 & 1.52 & 6 & |يُنظم برنامج تقويم يومي لقياس ملى التقدم في مهارات الطلبة. & 83 \\
\hline 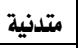 & 0.79 & 1.51 & 7 & | يراعي الفروق الفردية في التقييم. & 85 \\
\hline 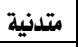 & 0.64 & 1.47 & 8 & |يستخدم وسائل التقويم المتنوعة والمناسبة لقياس مدى تحقيق الأهداف. & 75 \\
\hline 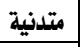 & 0.73 & 1.45 & 9 & |يُوجه أسئلة أثناء اللدرس للتاكدل من تحقيق كل هدف قبل الاتتقال لغيره. & 77 \\
\hline 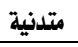 & 0.65 & 1.38 & 10 & | يلاحظ سلوكات الطلبة ويقوم بتسجيلها في السجلات الخاصة. & 76 \\
\hline 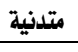 & 0.68 & 1.35 & 11 & | يستخدم تتائج التقويم في تحسين عملية التدريس وتوجيهها. & 81 \\
\hline 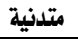 & 0.63 & 1.33 & 12 & |يُقيّيم أداء الطلبة بعد التدخل التربوي أو السلوكي باستخدام الأدوات المناسبة. & 87 \\
\hline 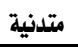 & 0.57 & 1.29 & 13 & | تفطي اختباراته المحتوى المعرفي للمادة. & 82 \\
\hline
\end{tabular}

(r) الدرجة القصوى (r)

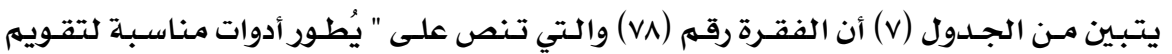

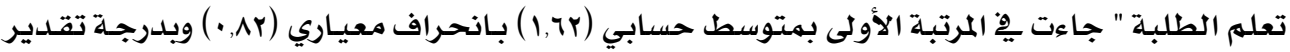

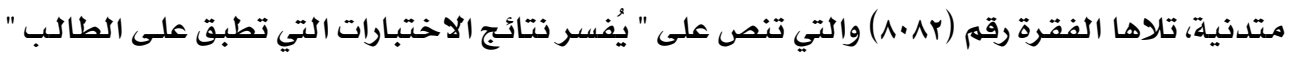

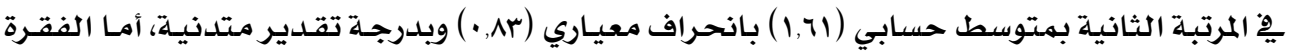

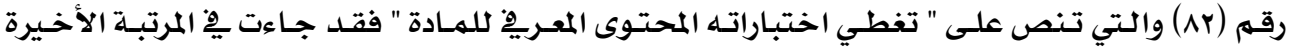

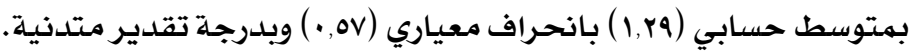

\section{هناقشة النتائج والتوصيات}

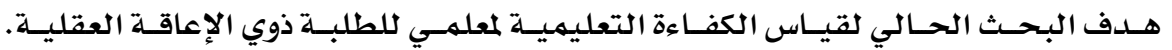

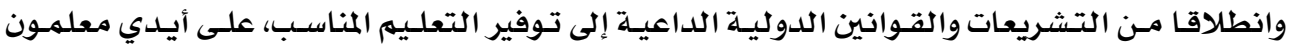

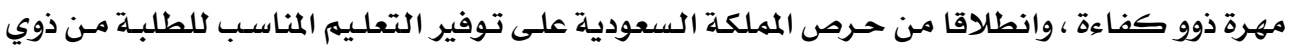




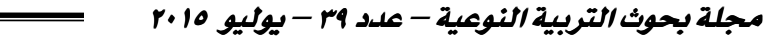

الإعاقة العقليـة، كل ذلك دفع البـاحث لإجـراء دراستـه الحالية مـن أجـل الكشف عـن مستوى الكفـاءة التعليميـة لمعلمي الطلبـة ذوي الإعاقة العقليـة. النتائج المتعلقة بالسؤال

مستوى الكفـاءة التعليميـة لمعلمـي الطلبسة ذوي الإعاقة العقليـة يخ المملكسة السعوديـة. حيـث أظهـرت المتوســات الحسسابية والانحرافـات المعياريسة لأداء المعلمسين على أبعـاد المقيـاس وعلى المقيـاس

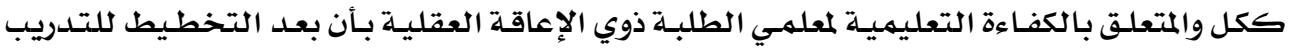

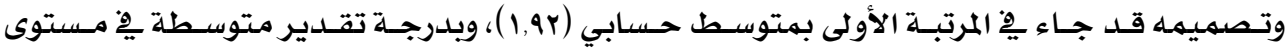
الكفاعة التعليميـة

ويعزو البـاحث ذلك إلى أن كفايـة التخطيط للتدريس وتصميمـه مـن الكفايـات المهمهـة جـدا

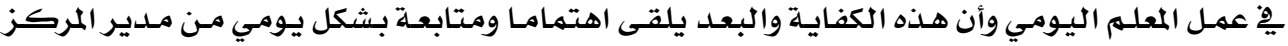
ومسن المشرفين سـواء مـن المجلسس لـشؤون الأفراد المعـوقين أو وزارة التتهميـة الاجتهماعيـة، لـذلك يـشعر المعلم بالقلق وعدم الارتياح لأنه موضـع مـراقبـة، مهـا يدفعـه دائمـا إلى الإعداد وانجـاز هـذا البعـد بـشكل مناسب وجيد، ومـن خلال خبرة الباحث ومـلاحظة أداء المعلمـين داخل المراكز، وجد أن بعد التخطيط للتـدريس وتصهيمـه لكل طفل يتهم بنـاءه و تطويره من قبل المدرس، بـالتعـاون مـع المديرة أو المدير الفـني والتعـاون مـع أكثر مـن زميـل، وهــا الاهتهـام يـنعكس على بعـد التخطـيط للتــريس بـشكل ايجـابي.

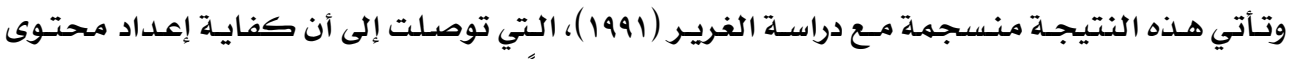

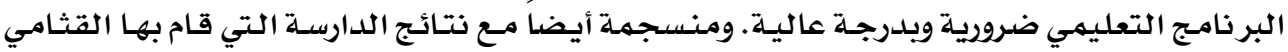

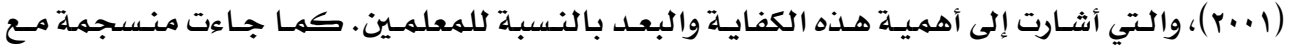

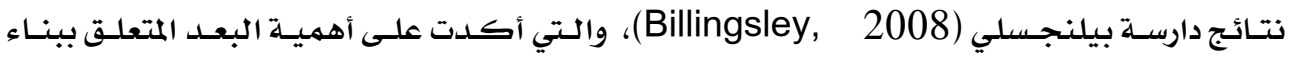
البرنامـج التربوي الفردي واتصاله بكفايتهم مِّه العمل .

أمـا يِّ ما يتعلق بـالبعد الثاني (الإدارة الصفيـة) فقد جاء يِّ المرتبـة الثانيـة بهتوسط حسسابي مقداره ( ع. 1, ) وبلدرجة تقدير متدنيـة، ويعزو البـاحث ذلك إلى أن المعلمـين له يتعرضـوا للتدريب على

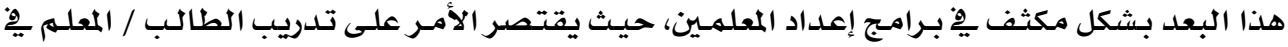

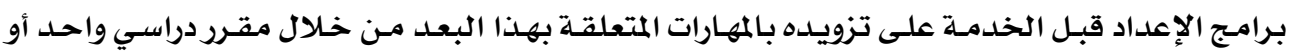

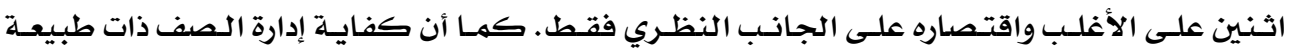
عمليـة تنهـى مـع الخبرة، والممارسـة العمليـة ِِِ أثنـاء الخدمـة (فترة التـدريس)، والتدريب على تطوير برامـج تعديل السلوتك وتطبيقها .

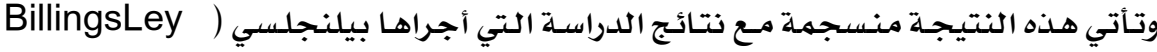
2008)، حيـث أشـارات النتـائج إلى أن جميـع العـاملين يخ تـدريس الطلبــة ذوي الإعاقـة العقليـة أكسلدوا

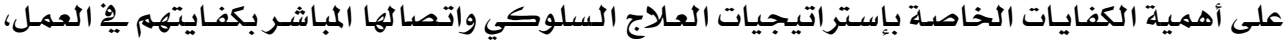
كما أكد المعلمون على حاجتهم المتوسطة للتدريب على هـذا المجـال أثنـاء الخدمـة. وجـاءت النتـائج

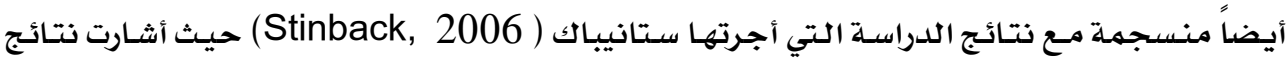




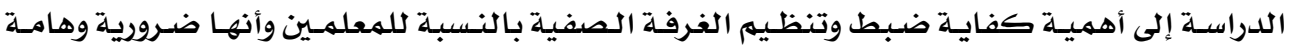
للعمل مـع الطلاب ذوي الإعاقة العقلية.

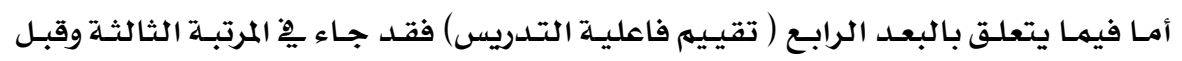

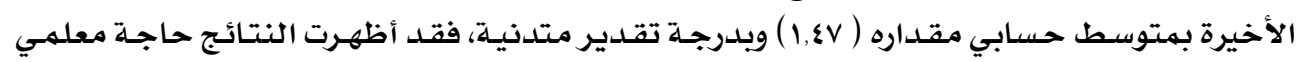

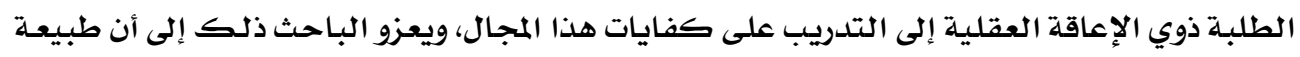

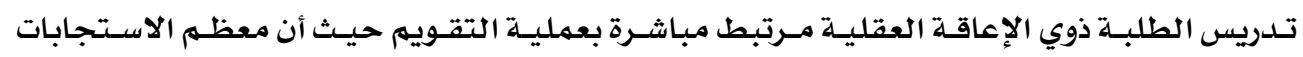

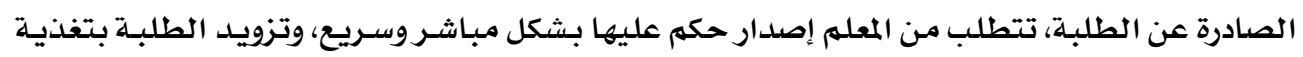

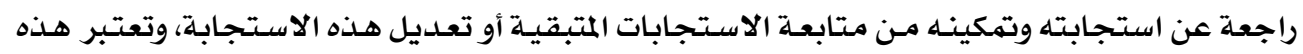

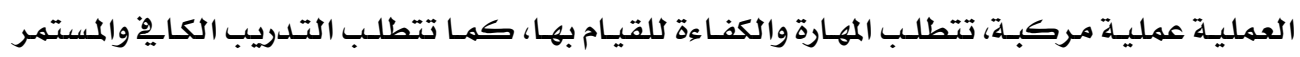

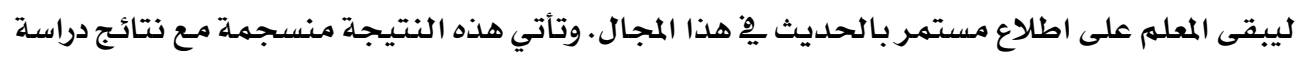

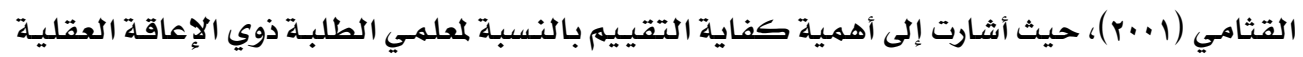

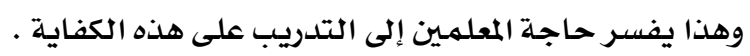

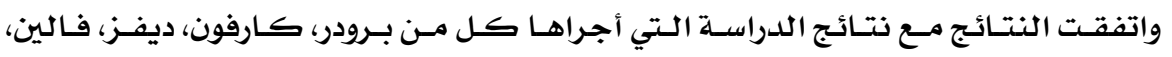

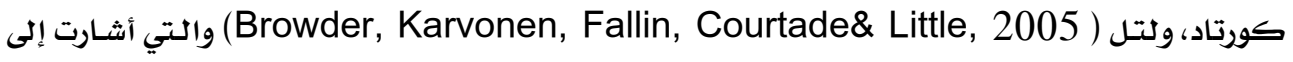

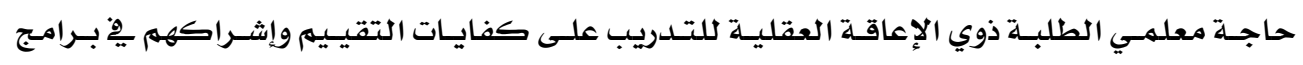
تدريبية . كما اتفقت النتائج مع نتائج الدراسة التي قام بها بويك ( Bouck, 2014 (

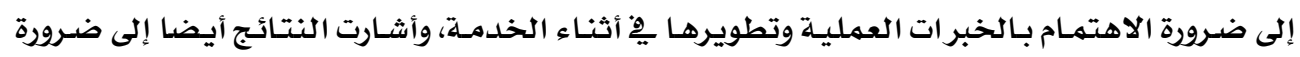

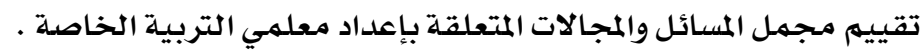

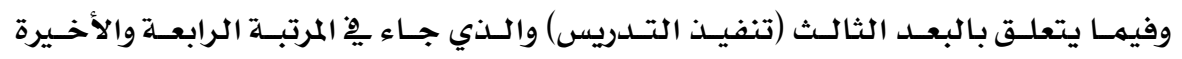

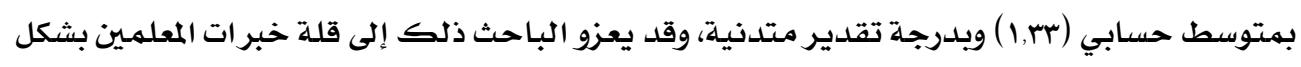

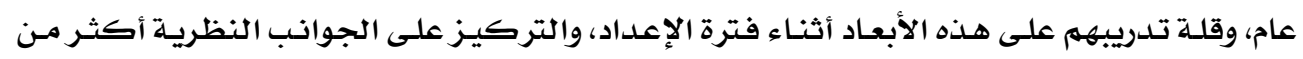

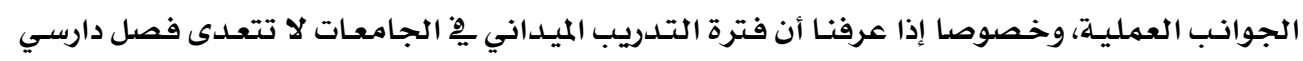

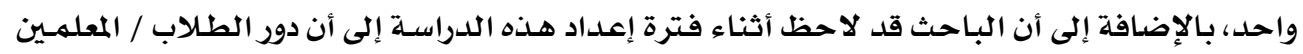

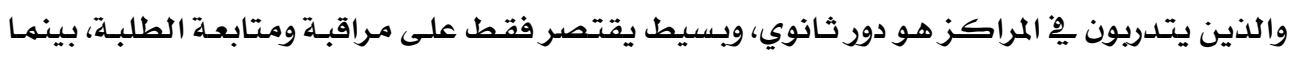

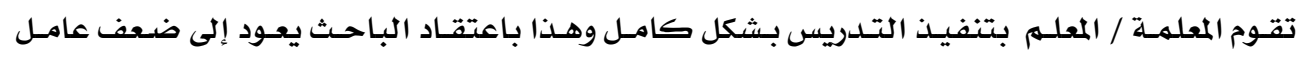

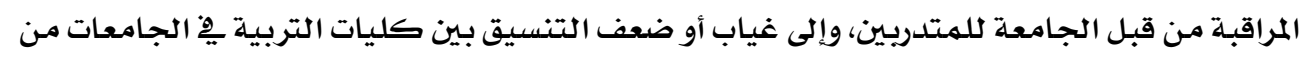

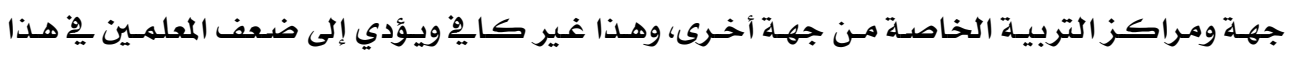

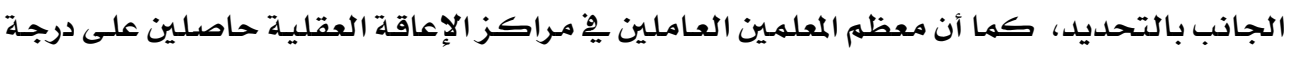

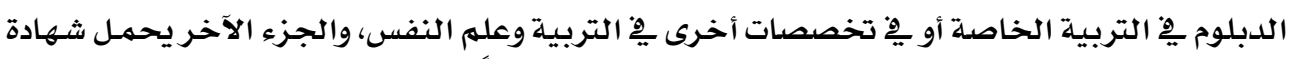

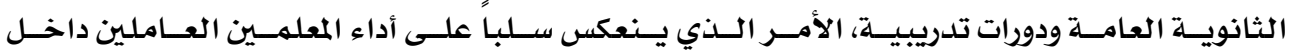




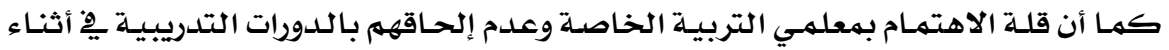

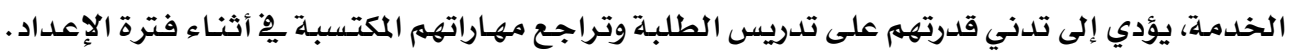

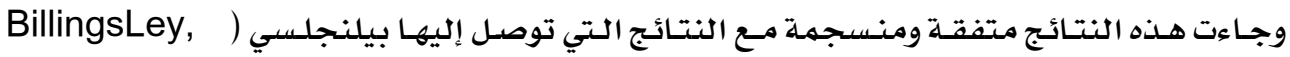

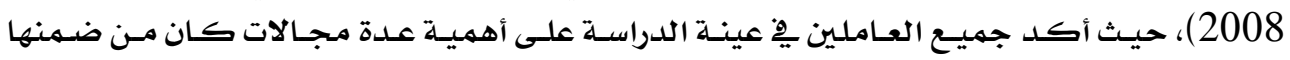

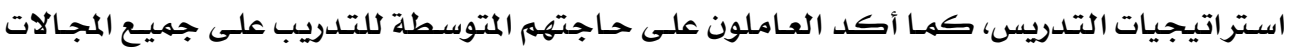

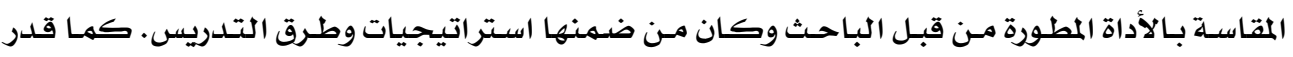

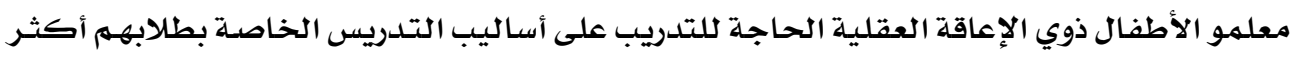

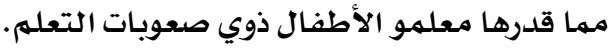

كهـا و اتفقت نتـائج الدراسـة الحاليـة مـع نتائج الدراسـة التي قـام بهـا مـركـز الاختبـارات

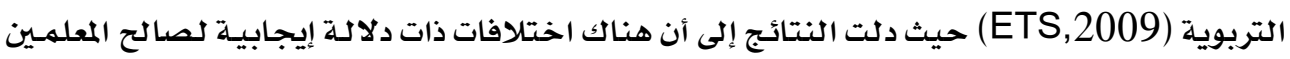

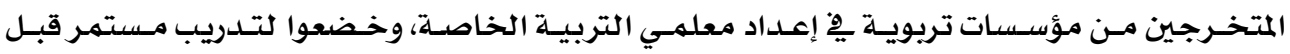

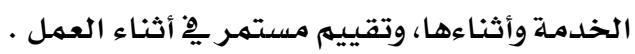

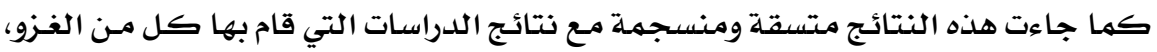

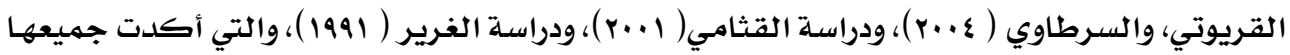

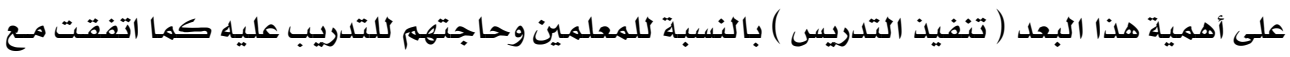

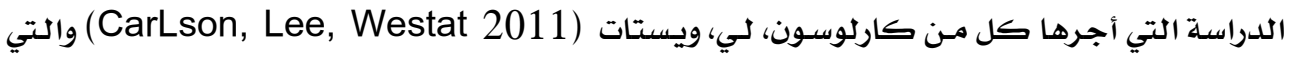

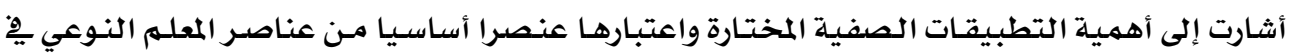

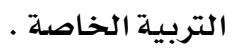

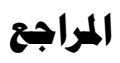

\section{المراجع باللفة العربية}

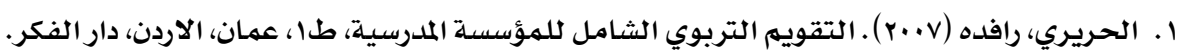

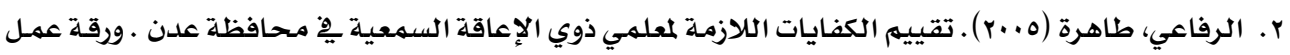

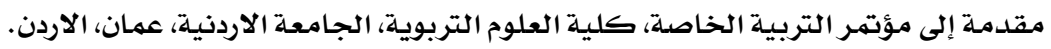

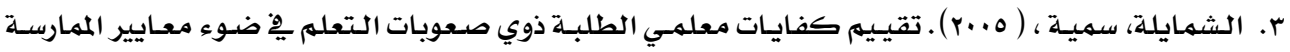

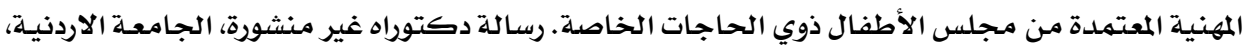
عمان، الاردن.

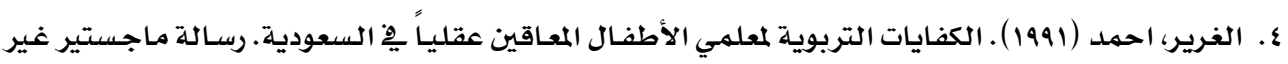
منشورة، الجامعة الاردنية، عمان، الاردن.

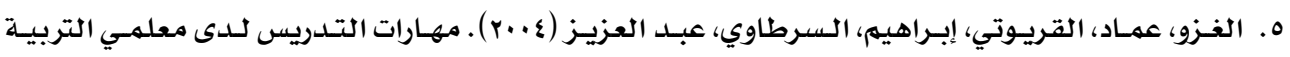

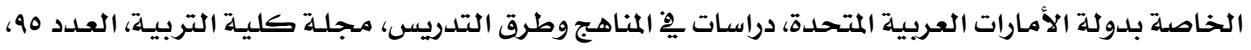

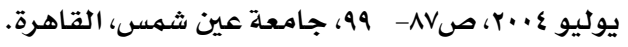




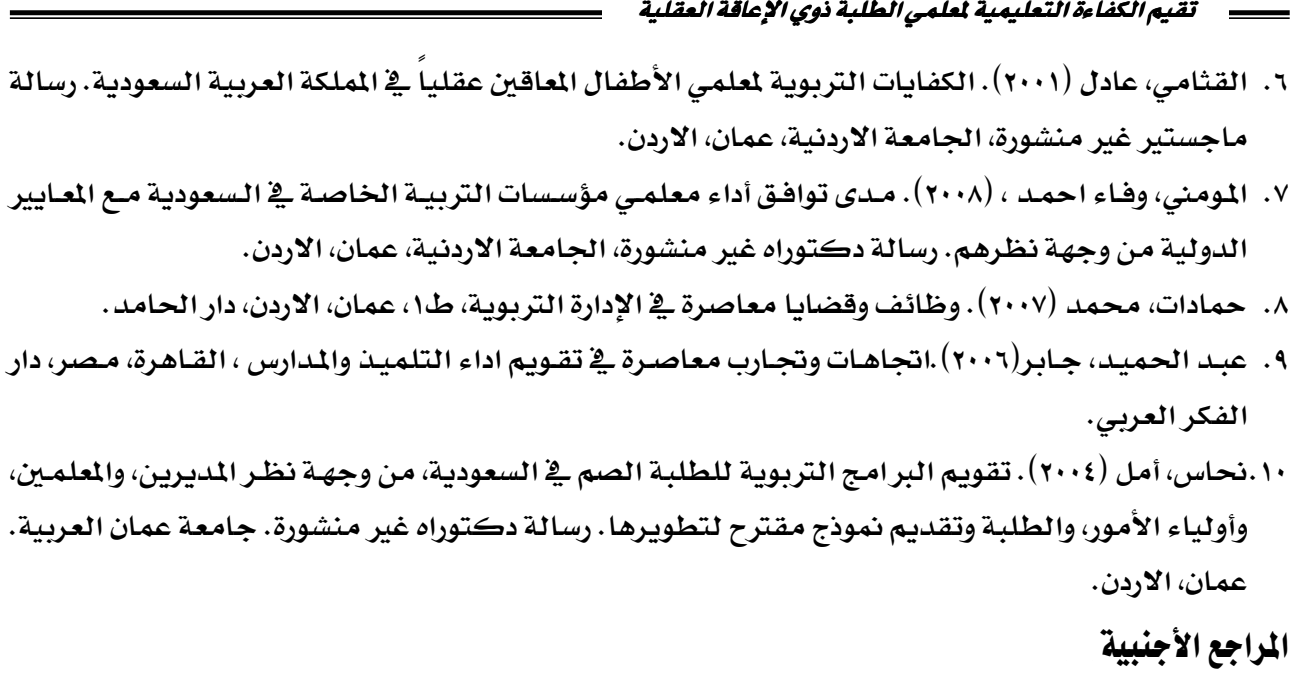

1. American Association on Intellectual and Developmental Disabilities. (2010). Intellectual Disability: Definition, Classification, and Systems of Supports.11th Ed, the AAIDD Ad Hoc Committee on Terminology and Classification, Washington.

2. Aysan, C., \&Yildiz, U. (2014). Special Education Teacher and Literary Acquisition in Children with Mental Retardation: A semi-structured interview. Educational Science: Theory \&Practice, Vol.4, 2, P264-270.

3. Billingsly, B. (2008). A Comparison of Staff Development Needs of Beginning and Experiment Special Education Teachers of the Mild Disabled, DAI-A53/05, 1481, Nov.

4. Bouk, E., C. (2014). Secondary Special Education: Perspective of Pre-service Preparation and Satisfaction. Teacher Education and Special Education, Vol. 27.N0 400,000.

5. Browder, D., Karvonen, M., Davis, S., Fallin, K., Courtade, M., \&Little, G. (2005). The Impact of Teacher Training on State Alternate Assessment Scores. Exceptional Children, Vol, 71, 3, p267-282.

6. Carlson, E., Lee, H.\& Westat, K. (2011), Identifying Attributes of High Quality Special Education Teachers. Teacher Education and Special Education, Vol. 27.No 4,000-000.

7. Debra, A., Neubert, Sherril, Moon, Mag, Grigal \& Vanessa, R. (2011). Post Secondary Educational Practices for Individuals with Mental Retardation and 
other Significant Disabilities: A review, of the literature. Journal of Vocational Rehabilitation, Vol. 16, 3/4, p15.

8. Emily, C., \& Bouck. (2013). Exploring Secondary Special Education for Mild Retardation Impairment. Remedial \&Special Education, Vol.25, 6, p367-390

9. ETS, (2009). Journal of Special Education. (2005), Vol, 11. No9, p11.http: //www.ETS.edu.

10. Foreman, Phill. (2009). Education of Students with an Intellectual Disability: Research and Practice, Information Age Publishing Inc, U.S.A

11. Hallahan, D., P. \& Kauffman, J., M. (2006). Exceptional Learners: Introduction to Special Education, (10th Ed) New Jersey, Englewood Cliffs: Prentice-Hall.

12. Hallahan, Daniel, P., Kauffman, James, M., \& Pullen, Paige, C. (2009). Exceptional Learners: An Introduction to Special Education.11td Ed, Pearson Education, Inc, New Jersey.

13. Ross, S. (2012). Teacher Feeling of Competency in Educating -Children with Special Needs in the General Education Setting, Dissertations, Master Thesis, (042).

14. Smith, Deborah \& Tyler, Naomi. (2010). Introduction to Special Education, Making A Difference. 7td Ed, Pearson Education, Inc, New Jersey.

15. Stainback, M. (2006). Training Teacher for the Severely and Profoundly Handicapped. Journal of Applied Behavior Analysis, Vol, 17.No2, p32-44. 


\section{The Teaching Competence Teachers of Students with Intellectual Disabilities \\ Dr. Derar Mohammad Mahmoud ALqudah}

\section{Study summary}

The purpose of this study was to evaluate the level of teaching competence of Saudi Arabia teachers of students with intellectual disabilities teachers

To achieve the aim of this study, the researcher used the descriptive as well as the experimental approaches. The researcher developed a scale to explore the level of educational efficiency of teachers of students with intellectual disabilities. This scale consisted of 87 items distributed on four domains. Its reliability and validity were calculated.

The researcher administrated the scale on a sample of (102) male and female teachers working in special education centers for students with intellectual disabilities. The participants were chosen randomly from Mecca, Jeddah governorates.

To answer the question of the study which is related to the teaching competence of teachers of students with intellectual disabilities, means and standard deviations of teachers' performances on each domain of the scale and the scale as a whole were calculated. The findings were as follows:

- The first domain (planning and designing instruction) was ranked first with a mean of (1.92) and moderate efficiency degree.

- The second domain (class management) was ranked second with a mean of (1.54) and low efficiency degree.

- The fourth domain (Evaluating lesson efficiency) was ranked third with a mean of (1.47) and low efficiency degree.

- Executing the lesson domain came in the fourth and final rank with a mean of (1.33) and low efficiency degree. 